\title{
EFEITOS DA CALAGEM E DA INCORPORAÇÃO DE RESTOS DE CULTURA DE SOJA SOBRE FRAÇÕES DA MATÉRIA ORGÂNICA E ALGUMAS CARACTERISTICAS DE FERTILI- DADE DE UM LATOSSOLO SOB VEGETAÇÃO DE CERRADO
}

\author{
VINICIO MARTINS DO NASCIMENTO \\ Engenheiro Agrônomo
}

Orientador: Dr. ANDRÉ MARTIN LOUIS NEPTUNE

Dissertação apresentada à Escola Superior de Agricultura "Luiz de Queiroz", da Universidade de São

Paulo, para obtenção do título de

Mestre em Solos $\theta$ Nutrição de

Plantas.

\footnotetext{
PIRACICABA

Estado de São Paulo - Brasil

Novembro, 1981
} 
A meus pais e irmãos,

Dedico.

A minha esposa, Augusta, e minhas filhas, Martha e Jülia, Ofereço. 


\section{AGRADECIMENTOS}

Nossos sinceros agradecimentos a todas as Instituições ou pessoas que direta ou indiretamente participaram da realização desse trabalho, em especial:

- A Universidade Estadual Paulista "Julio de Mesquita Filho" e Universidade de São Paulo, que possibilitaram a minha participação no Curso de pós-Graduação.

- Ao Centro de Energia Nuclear na Agricultura (CENA), pela per missão para o desenvolvimento dos trabalhos de laboratōrio.

- Ao Conselho Nacional de Desenvolvimento Cientifico e Tecnolögico (CNPq), pela ajuda financeira concedida.

- Ao Prof. Dr. André Martin Louis Neptune, pela orientação se gura neste trabalho.

- Ao Departamento de Tecnologia da Faculdade de Ciências Agrá rias e Veterinárias de Jaboticabal, pela concessāo do laboratório para realização de algumas análíses.

- Aos Drs. Takashi Muraoca e Carlos Clemente Cerri, pelo incentivo e amizade.

- A Enga Agra Marla Aparecida Pessoa da Cruz, pelo apoio na condução do experimento no campo.

- Aos Engos Agros Salatier Buzetti e Carlos Henrique Matiolli pela colaboração nas anälises estatisticas.

- Ao Roberto Chelli pelas análises quimicas realizadas. 
- Aos funcionários da Seção de Fertilidade do Solo e Fertilizantes (CENA): João Ademir Salvador, Marileuza Aparecida Bassi, Sandra Maria Genaro Nicoleti, Jo sé Anderson Forti, Dacir Bortolita, Rudnei de Al meida Romani e Sandra Tereza Pereira, pela colaboração e amizade.

- Aos colegas Francisco Maximino Fernandes, Luiz de Souza Cor reia, José Renato Zanini, Marco Eustāquio de Sá, Olair José Isepon e Ademir Flörio, pelo apoio e amizade.

- Aos funcionários da Biblioteca da ESALQ, pelos bons serviços prestados.

- Ao Paulo José Costa pelos serviços de datilografia. 
Lista de Tabelas.......................... vi i i

Lista de Figuras........................

RESUMO ....................... $\quad x i$

SUMMARY $\ldots \ldots \ldots \ldots \ldots \ldots \ldots \ldots \ldots \ldots \ldots \ldots \ldots \ldots \ldots \ldots \ldots$

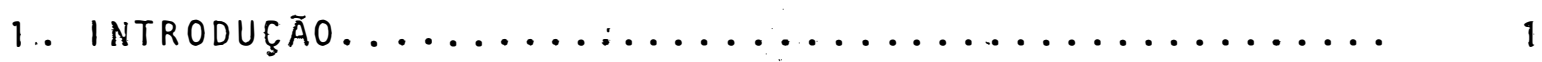

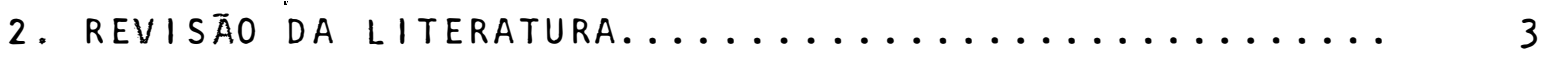

2.1. Efeito da calagem sobre as propriedades quimi-

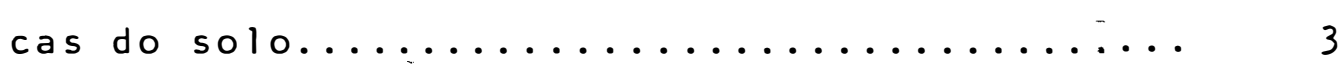

2.2. Consideraçōes gerais a respeito da matēria orgànica do solo (M.0.S.) e do seu fracionamento

2.3. Efeitos da matēria orgânica nas propriedades

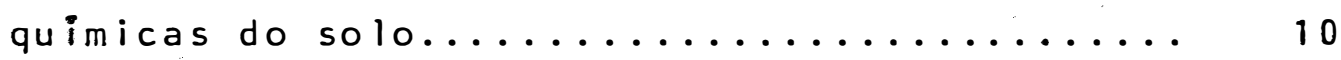

2.4. Efeitos da incorporação de materiais orgānicos sobre as propriedades quimicas do solo........

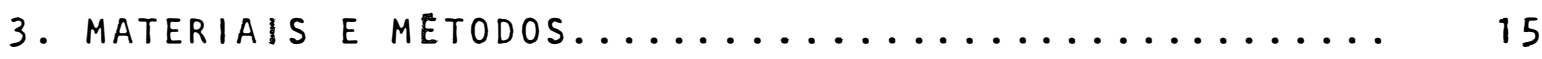

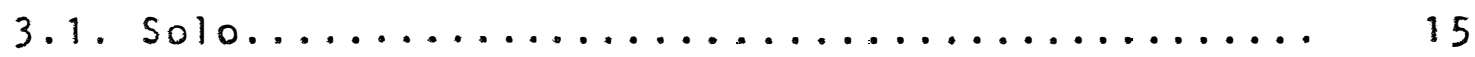

3.2. Delineamento experimental............. 17

3.3. Delimitação das parcelas................ 17

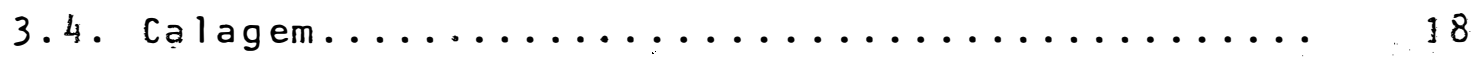

3.5. Produção, características químicas e incorpora ção dos resíduos vegetais................. 18

3.6. Amostragem de solo...................... 19

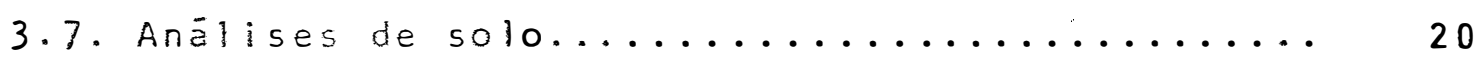

3.7.1. Determinação da umidade atual........ 20 
3.7.2. Determinação do pH.............. 20

3.7.3. Determinação de alumínio, potássio, cál cio + magnésio trocáveis e fósforo so-

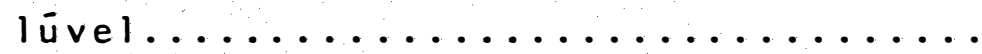

3.7.4. Determinação da capacidade de troca de

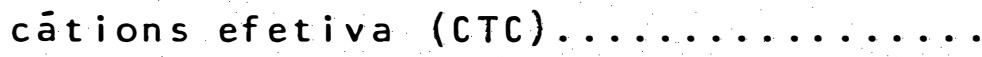

3.7.5. Determinação da porcentagem de saturação em bases $(v \%) \ldots \ldots \ldots \ldots \ldots \ldots \ldots \ldots$

3.7.6. Extração dos àcidos húmicos e fúlvicos 22

$3: 7.7$. Dosagem de carbono............. 23

3.7 .7 .1 . Carbono orgànico total..... 23

$3 \cdot 7.7 .2$. Carbono nas frações hümicas $\therefore \quad 23$

3.7 .8 . Dosagem de nitrogênio........... 23

3.7 .8 .1 . Nitrogènio total no solo.... 23

3.7.8.2. Nitrogènio total nas fraçōes.

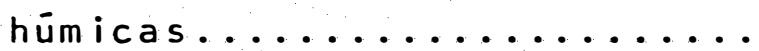

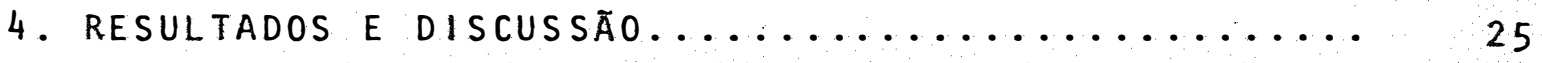

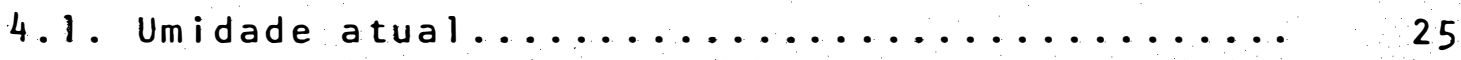

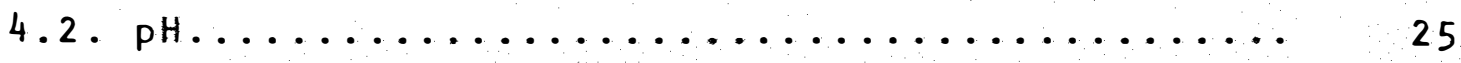

4.3. Aluminio trocável................... 26

4.4. Cálcio +magnésio trocäveis............ 27

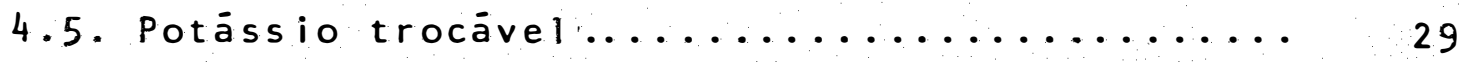

4.6. Fösforo solūvel.................... 29 
$v i i$.

Pàg .

4.7. CTC efetiva.................... 30

4.8. Porcentagem de saturação em bases $(V \%) \ldots \ldots . . .30$

4.9. Carbono nas frações da matéria orgânica..... 32

4.10. Nitrogênio nas fraçōes da matēria orgânica... 33

4.11. Relação $C / N$ nas frações da matëria orgânica.. 38

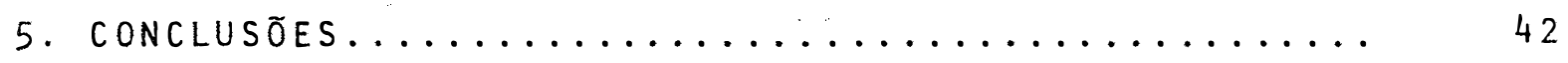

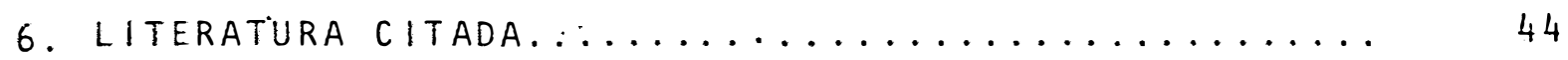




\section{LISTA DE TABELAS}

TABELA

Pàg.

1 Características químicas e granulométricas do solo da Fazenda Experimental da UNESP-"Campus" da llha Solteira, no local onde o presente experimento foi instalado (profundidade $0-20 \mathrm{~cm}$ )..... 16

2 Caracteristicas quimicas dos restos de cultu-

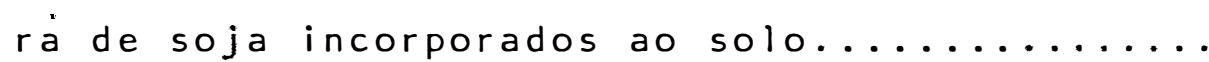

3 Valores de umidade atual, $\mathrm{pH}$ , aluminio trocável e cálcio + magnésio trocáveis nas profundidades de $0-20$ e 20-40 cm de um Latossolo Vermelho Escuro sob vegetação de cerrado submetido a diversos niveis de calagem e incorporação de restos de cultura de soja (1980/

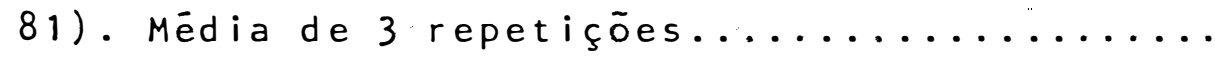

4 Valores de potássio trocável, fósforo solú vel, CTC efetiva e porcentagem de saturaçãoem bases nas profundidades de $0-20$ e $20-40 \mathrm{~cm}$ de um Latossolo Vermelho Escuro sob vegetação de cerrado submetido a diversos niveis de calagem e incorporação de restos de cultura de so ja $(1980 / 81)$. Média de 3 repetições...........

5 Valores de carbono orgānico total, carbono-ácidos hümicos, carbono-àcidos fülvicos e carbono-huminas (residuo) nas profundidades. de 0-20 e 20-40 cm de um Latossolo Vermelho Escu ro sob vegetação de cerrado submetido a diver sos niveis de calagem e incorporação de restos de cultura de soja (1980/81). Média de 3

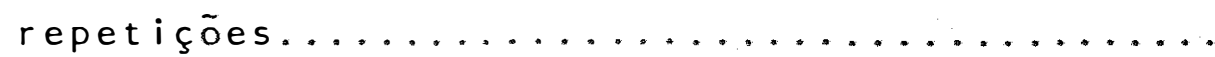


6 Valores de N-total no solo, N-äcidos hümicos, $\mathrm{N}$-ácidos fülvicos e N-huminas (residuo) nas profundidades de $0-20$ e 20-40 cm de um Latossolo Vermelho Escuro sob vegetação de cerrado submetido a diversos niveis de calagem e in corporação de restos de cultura de soja (1980/

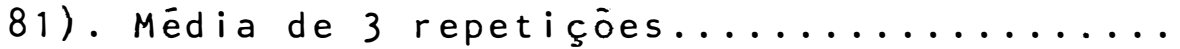

7 Relação C/N no solo, nós àcidos hümicos, nos ácidos fúlvicos e nas huminas (residuo) nas profundidades de $0-20$ e 20-40 cm de um Latossolo Vermelho Escuro sob vegetação de cerrado submetido a diversos niveis de calagem e incorporação de cultura de soja (1980/81). Mé-

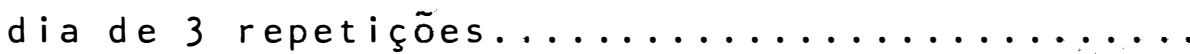




\section{LISTA DE FIGURAS}

FIGURA

Pàg.

1 Distribuição relativa do carbono nas frações da matēria orgânica em função de níveis de calagem em um Latossol Vermelho Escuro sob

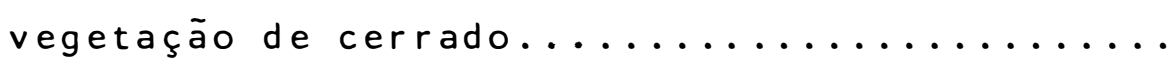

2 Distribuição relativa do nitrogênio nas frações da matēria orgânica em função de niveis de calagem em um Latossolo Vermelho Escuro

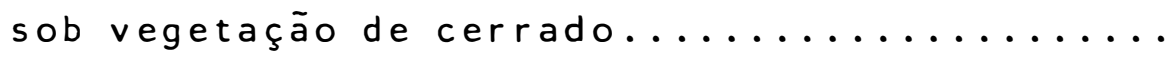

3 Distribuição relativa da relação C/N nas frạ ções da mátēria orgânica em função de nîveis de calagem em um Latosso Vermelho Escuro

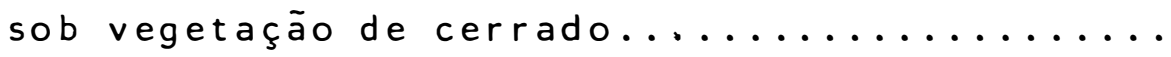




\title{
EFEITOS DA CALAGEM E DA INCORPORAÇĀO DE RESTOS DE CULTURA DE SOJA SOBRE FRAÇÕES DA MATÉRIA ORGÂNICA E ALGUMAS CARACTERISTICAS DE FERTILIDADE DE UM LATOSSOLO SOB VEGETACCÃO DE CERRADO
}

\author{
Autor: VINICIO MARTINS DO NASCIMENTO \\ Orientador: Dr. ANDRE MARTIN LOUIS NEPTUNE
}

RESUMO

Com o objetivo de estudar os efeitos da calagem e da incorporação de restos de cultura de soja em värias características de um Latossolo sob vegetação de cerrado, instalou-se um experimento de campo na Fazenda Experimental da UNESP - "Campus" de llha Solteira, MS.

As doses de calcário aplicadas, em t/ha, no ano agricola $1979 / 80$ foram: 1,$4 ; 2,8 ; 4,2$ e 5,6. Houve um tratamento que não recebeu calcário.

No ano agrícola' $1980 / 81$ foram incorporados 1,9 t/ha de restos de cultura de soja em todos os tratamentos.

Amostras do solo, tomadas nas profundidades de 0-20 e 20-40 cm, foram analisadas quanto a: umidade atual; $\mathrm{pH} ; \mathrm{Al}^{3+} ; \mathrm{Ca}^{2+}+\mathrm{Mg}^{2+} \mathrm{eK}^{+}$trocáveis; $\mathrm{P}$-solüvel; CTC; porcentagem de saturação em bases; carbono e nitrogênio em fraçōes da matéria orgànica. 
Entre as caracteristicas estudadas nas amos tras, constatou-se que houve aumento no valor pH e na porcentagem de saturação em bases, assim como diminuição do $\mathrm{Al}^{3+}$ trocável na profundidade de $0-20 \mathrm{~cm}$, nos tratamentos nos quais foram aplicados calcário.

A distribuição do carbono nas frações húmicas, em relação ao carbono orgânico total, foi de 4,25 e 58\%, res pectivamente, para ácidos húmicos, ácidos fülvicos e huminas ou residuo nas duas profundidades estudadas.

A distribuição do N-total, nas mesmas fraçōes, foi de 4,32 e $41 \%$, respectivamente, para ácidos hūmicos, ác dos fúlvicos e huminas em relação ao N-total do solo para as duas profundidades.

A respeito da $r$ elação $C / N$, no solo e nas frações húmicas, não se verificaram variaçōes apreciáveis em fun ção dos tratamentos e das profundidades. 


\section{EFFECTS OF LIMING AND SOYBEAN CROP RESIDUES \\ ON THE SOIL ORGANIC MATTER FRACTION AND SOME CHARACTERISTICS OF FERTILITY OF AN ACRUSTOX IN THE ACID SAVANNAS CONDITIONS}

Author: VINICIO MARTINS DO NASCIMENTO

Adviser: Dr. ANDRE MARTIN LOUIS NEPTUNE

SUMMARY

With the aim of studying the effects of liming and incorporation of soybean crop residues on some characteristics of an Acrustox in the acid savannas conditions (cerrado conditions), a field experiment was carried out at the Experimental Station of the Universidade Estadual Paulista "Julio de Mesquita Filho"-Campus de llha Solteira, in the Mato Grosso do Sul State, Brazil.

The rates of lime in tha applied in october 1979 were: $1.4 ; 2.8 ; 4.2$ and 5.6 . There was a treatment with no $1 \mathrm{iming}$.

$$
\text { In June 1981, residues of soybean crop, }
$$

evaluated in $1.9 \mathrm{t} / \mathrm{ha}$. were incorporated in all the treatments.

$$
0 n \text { soil samples taken at depths of } 0-20 \mathrm{~cm} \text { and }
$$

20-40 cm, actual humidity, $\mathrm{pH}$, exchangeagle $\mathrm{Al}^{3+}, \mathrm{Ca}^{2+}+\mathrm{Mg}^{2+}$ and $\mathrm{K}^{+}$, 
soluble P, CEC, \% of bases saturation and fractions of soil organic matter, were determined.

The data showed an increase in the pH value and $\%$ of bases saturation and a diminution in the exchangeable $\mathrm{Al}^{3+}$, at the depth of $0-20 \mathrm{~cm}$, in the treatments in which lime was applied.

The distribution of carbon in the humic fractions, related to the total organic carbon, was $4 \%, 25 \%$ and $58 \%$, respectively, for humic acids, fulvic acids and humin, at both depths.

The distribution of total $N$ in the same fractions, was $4 \%, 32 \%$ and $41 \%$, respectively, for humic acids, fulvic acids and humin, in respect to the total soil N, at both depths.

The C/N ratio in the soil and humic fraction showed no significant variations. 


\section{INTRODUÇÃO}

os solos das regiões tropicais, nos quais es tão incluídos os da região dos cerrados brasileiros, apresentam-se bastante intemperizados com predominância de argilas do tipo 1:1, óxidos de ferro e alumínio, o que resulta numa CTC quase que totalmente dependente da matéria orgánica.

Por outro lado, esses solos são, no geral, bas tante arejados, o que favorece sobremaneira os processos de xidação, com reflexos no teor de humus a ser formado.

Nessas condições, o conhecimento das transfor mações da matéria orgánica é de fundamental importáncia para a adoção de práticas de manejo adequadas.

A produtividade agrícola dos solos das regiões tropicais sob clima ümido é limitada principalmente pelas suascaracteristicas químicas, entre as quais a pobreza de cálcio e magné 
sio, a alta acidez e a toxicidade por alumínioe manganês. Des sa maneira, a calagem, nesses solos, torna-se uma prática indispensável para melhorar as condiçōes de fertilidade e consequentemente possibilitar a elevação dos níveis de produção. Considerando que a inda não são bem conhecidos os efeitos da calagem sobre as propriedades químicas e fra ções da matéria orgânica desses solos, foi realizado este trä balho com o objetivo de estudar os efeitos da calagem nas fra ções da matéria orgānica e de outras características de um La tossolo sob vegetação de cerrado ao qual foi incorporado restos de culturá de soja. 


\title{
2. REVISÃO DA LITERATURA
}

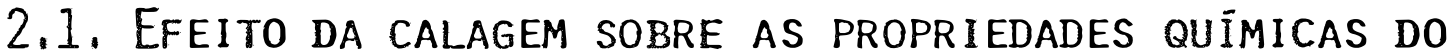 SOLO}

\begin{abstract}
A calagem é uma prática agrícola que se utiliza desde os tempos remotos para melhorar a produtividade dos solos ácidos, embora ABRUNA et alie (1964); CATANI e GALLO (1955), consideram que o uso do calcário nos trópicos é peque no ou se encontra em fase experimental.

Nos solos de drenagem livre das regiōes tropicais, a necessidade de calcário é devida à pobreza de bases, acidez elevada e à presença de óxidos de alumínio e ferro. De acordo com BLACK (1957), COLEMAN et alii (1958) e MEHLICH e COLEMAN (1952), a calagem é a incorporação ao solo de carbonatos, hidröxidos e öxidos de cálcio e magnésio,
\end{abstract}


visando à correção dos efeitos nocivos da acidez elevadae aumentar o suprimento de cálcio e magnésio para as plantas.

os aumentos na produção das culturas obtidos pelo emprego de calcārio são os mais diversos ..possíveis, talvez devido à sua granulometria ou ao seu valor de neutraliza ção ou até a prōpria maneira de se calcular as doses a serem aplicadas (Rios et alii, 1978, citados por SOUZA e NEPTUNE, 1979).

Segundo PRATT (1966), GARGANTINI et alii (1970), existe uma relação entre porcentagem de saturação em bases e o pH, sendo que, à medida que se eleva a disponibilidade de bases trocáveis, aumenta o pH e diminui o teor de Al trocável.

VAN RAIJ et alii (1977), estudando o efeito de niveis de calcārio sobre a produção de soja em solo sobj vegetação de cerrado durante 3 anos, encontraram efeito favorà vel de calagem na produção de grãos, sendo que as produçōes máximas coincidiram com os valores pH próximos de 6,0 e para teores de $\mathrm{Ca}^{2+} \mathrm{e} \mathrm{Mg}^{2+}$ ao redor de $3,0 \mathrm{~m}$.eq/100 ml TFSA.

Estudando os efeitos da granulometria de calcä rio dolomitico nas propriedades químicas do solo, SOUZA e NEP TUNE (1979) encontraram, para a profundidade de $0-20 \mathrm{~cm}$, as me lhores condiçōes químicas para o desenvolvimento das plantas, tais como: maiores valores de $\mathrm{pH}$, de $\mathrm{Ca}^{2+}$ e $\mathrm{Mg}^{2+}$ trocáveis e meno res valores de $\mathrm{Al}^{3+}$ trocável e de acidez titulävel. Além disso, os melhores resultados para as caracteristicas estudadas foram obtidos aos 270 e 520 dias após a calagem. 
A capacidade de troca de cátions (CTC), ou car ga negativa dos colóides, cuja neutralização depende da reação do solo, é característica de vários minerais de argila e da matéria orgânica. Assim, de acordo com WIKLANDER (1964) com o aumento ou diminuição do pH, há também aumento ou diminuição da CTC dentro de certos limites.

HALSTEAD et alii (1958) neutralizaram a acidez de quatro solos podzóis do Canadá com diferentes quantidades de carbonato de cálcio e carbonato de magnésio, numa amplitude de variação da relação Ca/Mg entre 0,6 e 19,5; os resultados, embora sem mostrar efeitos sobre os rendimentos da alfafa, evidenciaram a diminuição de Ca trocável por influência do $\mathrm{MgCO}_{3}$.

0 problema da calagem é bastante complexo e a quantidade de corretivo a ser aplicado ao solo pode variar de acordo com o objetivo que se tem em vista (CATANI e JACINTO, $1964)$.

\subsection{CONSIDERAÇões gERAIS A RESPEITO DA MATÉRIA ORGÂNICA DO SOLO $\left(M .0 . S_{.}\right)$E DO SEU FRACIONAMENTO}

A matéria orgânica do solo pode ser classifica da em dois grupos principais: substâncias húmicas (humus) e substâncias não-húmicas. Enquanto as substâncias não-húmicas são de natureza química definida, as substâncias hümicas são bastante complexas e de natureza quimica não bem definida. 
Para DABIN (1976), o humus é a matéria orgànica de cor escura que apresenta uma granulação bastante fina e se encontra completamente misturada à matéria mineral do solo.

De acordo com KONONOVA (1966), substāncias hümicas são aquelas de natureza complexa, coloração escura, pró veniente da decomposição de vegetais e solúveis em álcalis.

Apesar da natureza química complexa da matēria orgànica humificada, inūmeras pesquisas mostram que seus componentes podem ser fracionados de acordo com suas solubilidades em diferentes solventes.

Segundo Duchaufour (1970), conforme citado em VOLKOFF e ANDRADE (1975), as fraçōes da matēria orgânica humi ficada estão reunidas em très grupos principais, ou seja, àcidos fülvicos, àcidos hümicos e huminas ou resíduo.

VOLKOFF e ANDRADE (1975) caracterizaram a maté ria orgânica de alguns solos ferralíticos do Estado da Bahia, encontrando resultados que evidenciam que nos harizontes mais superficiais, a quantidade de matéria orgânica não decomposta ("matéria orgânica leve") é baixa em virtude da deoomposi ção muito rápida dos detritos vegetais. Concluiram ainda, que devido à alta humificação, à instabilidade dos compostos hümi cos formados, à abundāncia de frações de pequena massa molecu lar e à grande migração dessas frações no perfil desses solos, a matéria orgànica desempenha um importante papel na mobilização dos elementos minerais. 
ANDREAUX e BECERRA (1975), em trabalhos de frä cionamento e caracterização do material hūmico de vārios oxís solos colombianos, concluíram que, naqueles solos, o ciclo da matéria orgānica é muito rảpido, caracterizando-se por uma in tensa mineralização dos restos vegetais e que, na maioria dos solos estudados, o teor de matēria orgānica não decomposta ë muito baixo.

Com vistas aos processos de mineralização e humificação da matéria orgânica, pelo fato de serem principal mente processos microbiológicos, deve-se considerar que qualquer evento que desfavoreça a microflora do solo, terá reflexos negativos nas transformações desse material. Neste aspecto a calagem assume papel importante pois eleva o valor pH e os teores de Ca e de Mg e, segundo FASSBENDER (1978), a maior parte das bactérias e actinomicetos desenvolvem-se melhor sob pH próximo da neutralidade.

Mishustin (1956), c itado por KONONOVA (1966), constatou que solos da URSS muito ricos em humus sāo caracterizados por moderado nümero de microrganismos, o que lhe permitiu concluir que a moderada atividade microbiológjca, é favorável ao acūmulo de humus no solo.

PRIMAVESI (1973), em levantamentos de solo no Rio Grande do Sul, encontrou boa correlação entre teor de cá cio no solo e matèria órgànica humificada, sendo que, à medida que se aprofundava no perfil, diminuia a quantidade de hamus. 
Para Russel e Russel (1961); Schapevel e Kruse (1971), conforme citado em PRIMAVESI (1980), a idéia de que quanto mais cálcio tiver o solo menor será o seu teor em humus nem sempre é verdadeiro. De acordo com esses pesquisadores, será válido quando se tratar de calagem e de aumento de pH do meio e, não para o caso de quantidades de cálcio natu ralmente existentes no solo.

As substáncias hümicas podem apresentar composição e propriedades diferentes em função do material origi nal, do meio em que se desenvolveram e da idade. Assim, os äcidos hümicos, por exemplo, podem apresentar diferentés teo res de carbono, nitrogênio, alēm de grandes diferenças em outras propriedades determinadas pelas condições em que se formaram.

$$
\text { DORADO et alii (1973) estudaram as substān- }
$$

cias hümicas de três turfas espanholas, comparando-as com as de outros solos. Os resultados evidenciam que as turfas apresentam substáncias hümicas e capacidade de troca elevadas, cá racterizando-se por elevado teor de ions de troca. Constataram ainda, que as substāncias hümicas das turfas, além de apresen tarem elevado coeficiente àcido hümico/ácido fülvico, possuem um alto teor de ácidos himatometànicos.

$$
\text { POLO et alii (1978a), em estudos de fraciona- }
$$

mento e caracterização de ácidos hümicos de diversos ecossistemas florestais, encontraram que, no geral, houve um predomi nio de ácidos húmicos sobre os ácidos fülvicos nos solos estuda dos. Esses pesquisadores constataram, ainda, que a elevada propor 
ção de huminas encontrada está de acordo com as condições eco lógicas dos ecossistemas bem aerados, onde a lignina evolui rapidamente para compostos húmicos não extraíveis.

POLO et alii (1978b), estudando as transformações da matēria orgânica de solo acondicionado em frasco de vidro e submetido à incubação em estufa a $280^{\circ} \mathrm{C}$ e $70 \%$ de umida de, durante 135 dias, constataram que, durante o processo, hou ve uma diminuição progressiva nos teores de carbono e nitrogê nio e na relação $C / N$ ao lado de um aumento na capacidade de troca de cátions. Foi observado, ainda, que a incubação de hü minas possibilitou a solubilização de $10 \%$ do seu carbono total, o que foi atribuído a rupturas da união da matēria orgânica com a parte mineral.

ORTEGA et alie (1979) extrairam substâncias hü micas de diferentes materiais (esterco, lignito) e de um rend zina, encontrando, para os ácidos húmicos extraídos do esterco, teores mais elevados de nitrogênio e menor relação $C / N$, que foi próxima de 10. Para os ácidos húmicos extraídos do rendzina, a relação $C / N$ foi ligeiramente superior a 10 , enquanto que esta relação, para os ácidos hümicos do lignito foi prōximo de 60.

ALMENDROS e POLO (1980) estudaram as frações da matéria orgânica humificada em três tipos de solo desenvol vidos sob uma mesma vegetação, comparando-as com as frações húmicas obtidas diretamente das folhas das plantas. A filtração através de Sephadex mostra que os compostos pré - hümicos 
extraídos das folhas apresentam menor grau de polimerização que os àcidos hümicos da fração leve da matéria orgânica do solo.

$$
\text { Por outro lado, SCHNITZER e SKINNER (1968), com }
$$
pararam dois extratores do humus do solo, $\mathrm{NaOH} 0,5 \mathrm{Ne} \mathrm{HCl} 0,1 \mathrm{~N}$. Os resultados mostraram que a composição química dos dois extratos foi semelhante e que a extração com álcali não causou grandes modificaçōes na matéria orgànica estudada.

$$
\text { TOLEDO (1973) em trabalho de caracterização }
$$
química de um àcido hümico extraído de sedimentos de lago, utilizoú como extrator do humus uma solução de $\mathrm{NaOH} 0,5 \mathrm{~N}$ em at mosfera de $\mathrm{N}_{2}$.

\subsection{EFEITOS DA MATÉRIA ORGÂNICA NAS PROPRIEDADES QUİMICAS DO SOLO}

Värios elementos químicos podem ser complexados pela matéria orgânica e assim, formar compostos de varia da estabilidade no solo.

OADES e TOWNSEND (1963) estudando a influència do ferro na estabilidade da matéria orgânica do solo durante a peroxidação, verificaram que o ferro permaneceu complexado com o humus mesmo durante a oxidação do mesmo por peróxido de hidrogènio. 
AKINOLA e COREY (1973) estudando a relação entre pH, matéria orgánica e disponibilidade de nutrientes, encontraram um aumento significativo no teor de nutrientes no solo, com o aumento do teor de matēria orgânica.

THOMAS (1975) estudou a relação entre alumínio trocável e matēria orgānica em um solo ácido. os resultados in dicaram uma diminuição acentuada do Al trocável com o aumento do teor de matéria orgànica do solo.

Estudando a contribuição da matéria orgānica na capacidade total de trocá de cátions (CTC) do solo, SCHNITZER (1975) encontrou, para um solo com 10\% de matéria orgânića, u ma participação da mesma de aproximadamente $70 \%$ na CTC.

Procurando correlacionar teor de matēria orgánica do solo com aluminio trocável e acidez dependente de pH, HOYT (1977) encontrou correlação. positiva $(r=0,97)$ entre por centagem de matēria orgánica e acidez dependente de pH, enquanto que o Al trocável correlacionou negativamente $(r=-0,56)$ com a porcentagem de matēria orgànica.

De acordo com BLOOM et alii (1979), o aluminio trocável por ions $\mathrm{H}^{+}$nos sitios de troca da matéria orgánica e a hidrölise dos compostos de alumínio contribuem sobremaneira para o poder tampão do solo. Esses pesquisadores considera ram ainda que o manejo da matēria orgànica pode ser eficien-. te no abaixamento da atividade do $\mathrm{Al}^{3+}$ na solução do solo, re duzindo conseqüentemente, a sua toxidez. 


\subsection{EFEITOS DA INCORPORAÇÃO DE MATERIAIS ORGÂNICOS SOBRE AS PROPRIEDADES QUIMMICAS DO SOLO}

Os residuos vegetais que chegam ao solo influem diretamente na relação $C / N$ e, portanto, afetam os processos microbiolögicos de mineralização.

ESCOBAR et alii (1972) estudando os efeitos da adição de celulose e da temperatura na mineralização do nitro gênio em oxissolos, constataram que durante 30 dias o processo predominante na mineralização do nitrogênio foi a amonificação. A produção de $\mathrm{CO}_{2}$ aumeñtou significativamente com o au mento de temperatura e adição de celulose, sendo que as produções de $\mathrm{CO}_{2}$ e de $\mathrm{N}-\mathrm{NH}_{4}$ foram altamente correlacionadas.

MARTINEZ e BLASCO (1972) verificaram que a adi

ção de doses crescentes de resíduos vegetais ao solo aumentou a atividade microbiana do mesmo e diminuiu progressivamen te a nitrificação. Por outro lado, foi observado que teci dos vegetais com mais de $1,8 \%$ de nitrogênio, quando adiciona dos ao solo, promovem um estreitamento na relação $C / N$, ocasio nando uma predominância na mineralização.

BARBIERI et alii (1979) estudaram, em um Latos solo Vermelho Amarelo - fase arenosa, o efeito de cinco leguminosas, usadas como adubo verde, sobre várias características químicas do solo. Os resultados evidenciaram efeitos significativos para $\mathrm{N}-\mathrm{NO}_{3}$ aos 180 e 270 dias após incorporação, 
além de boa correlação entre carboidratos totais e a relação C/N no solo.

MELO et alii (1979), estudando o efeito da incorporação de resíduos culturais de Sorghum bicolor (L.) Moench (sorgo) e de Dolichos lab lab (L.) (labe-labe) sobre formas de carbono e nitrogênio em um Latossolo Roxo, encontraram, pạ ra os tratamentos que receberam residuos da cultura do sorgo, predominância na imobilização no período de 0-15 dias de incu bação, enquanto, no mesmo período, o tratamento testemunha man teve-se em equilíbrio e o tratamento que recebeu resíduos de cultura do labe-labe apresentou predominância sensível da mi neralização.

NASCIMENTO e MELO (1981), em trabalho de rotação de culturas e incorporação de restos culturais em solo sob vegetação de cerrado, constataram efeitos significativos da incorporação de diferentes materiais sobre pH, CTC, carbono-ácidos húmicos, carbono-huminas e N-äcidos fülvicos.

A utilização de resíduos orgânicos como adubo é uma prática que tem se mostradó eficiente, principalmente em culturas olerícolas, pois coloca em disponibilidade vários nutrientes. Assim, ALMEIDA et alii (1981), estudando o efeito de vārios adubos orgânicos: esterco de curral (40 t/ha), esterco de galinha (10 t/ha) e composto de $1 \mathrm{i} \times 0$ urbano $(40 \mathrm{t} / \mathrm{ha})$, com e sem adubação mineral, para cultura do tomateiro, encontraram, para a testemunha, uma produção significativamente me nor que os tratamentos com adubo orgânico. A suplementação 
com adubo mineral (NPK) proporcionou aumento de $47 \%$ na produção, enquanto que entre os tratamentos que sō receberam adubo orgánico, o que melhor se comportou foi o que recebeu esterco de galinha que proporcionou um aumento de $21 \%$ na produção em relação aos outros cuja produção situou por volta de 41.000 kg/ha. 


\section{MATERIAIS E METODOS}

\subsection{SoLo}

0 experimento foi conduzido em um solo originalmente coberto por vegetação de cerrado, situado na Fazenda Experimental da UNESP - "Campus" de llha Solteira, MS, classi ficado por DEMATTE (1980) como Latossolo Vermelho Escuro àlico, textura argilosa. As principais caracteristicas quimicas e granulométricas do solo são apresentadas na Tabela 1.

0 clima da região, classificado como Aw, carac teriza-se por uma temperatura média anual de $23,7^{\circ} \mathrm{C}$ com média dos meses mais quentes (janeiro e fevereiro) igual a $25,7^{\circ} \mathrm{C}$ e a dos meses mais frios (junho e julho) igual 20,60 C. A precipitação pluviométrica média anual está em torno de $1.300 \mathrm{~mm}$, predominantemente no período de outubro a março (DEMATTE, 1980). 


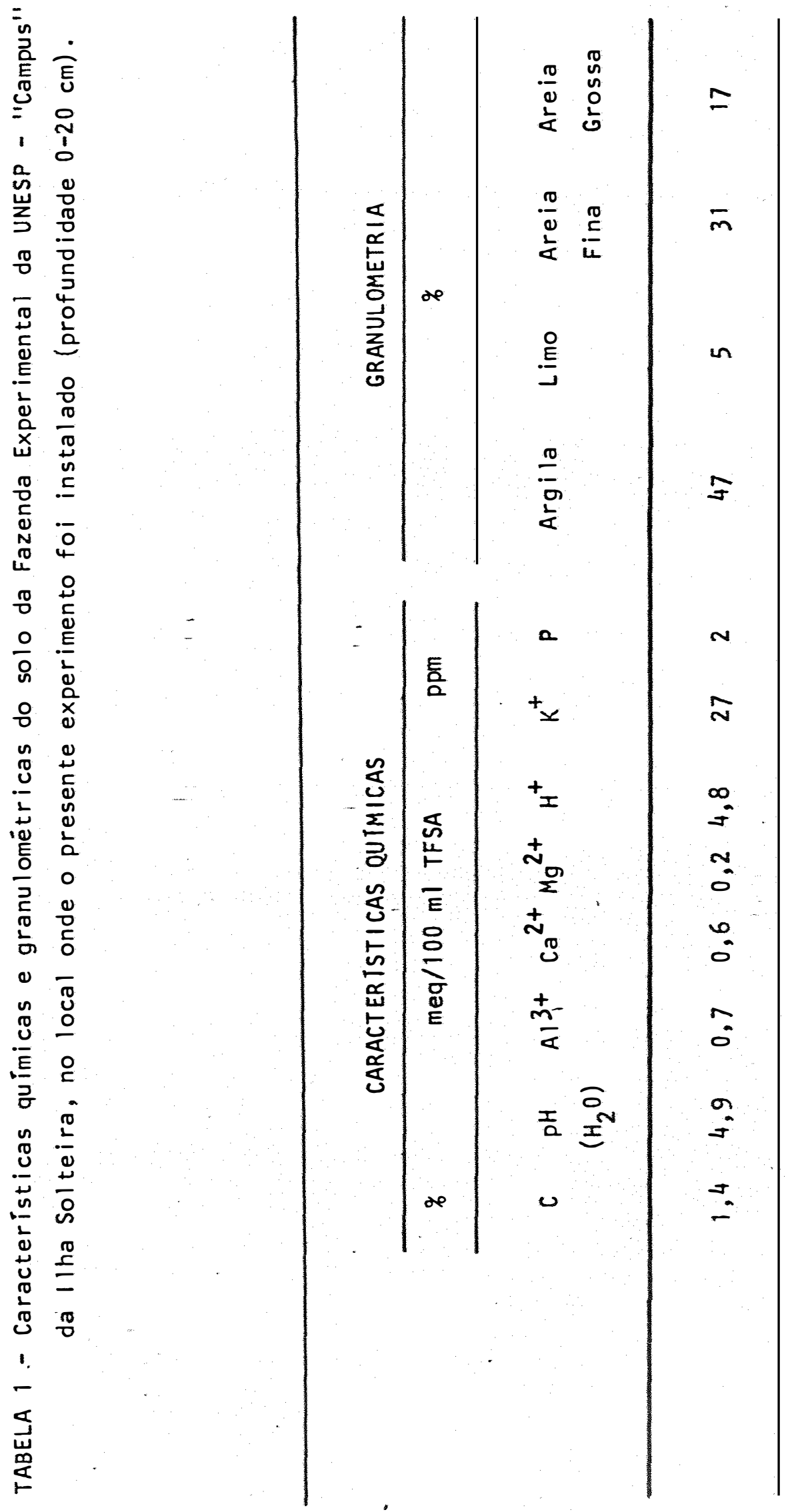




\subsection{Delineamento experimental}

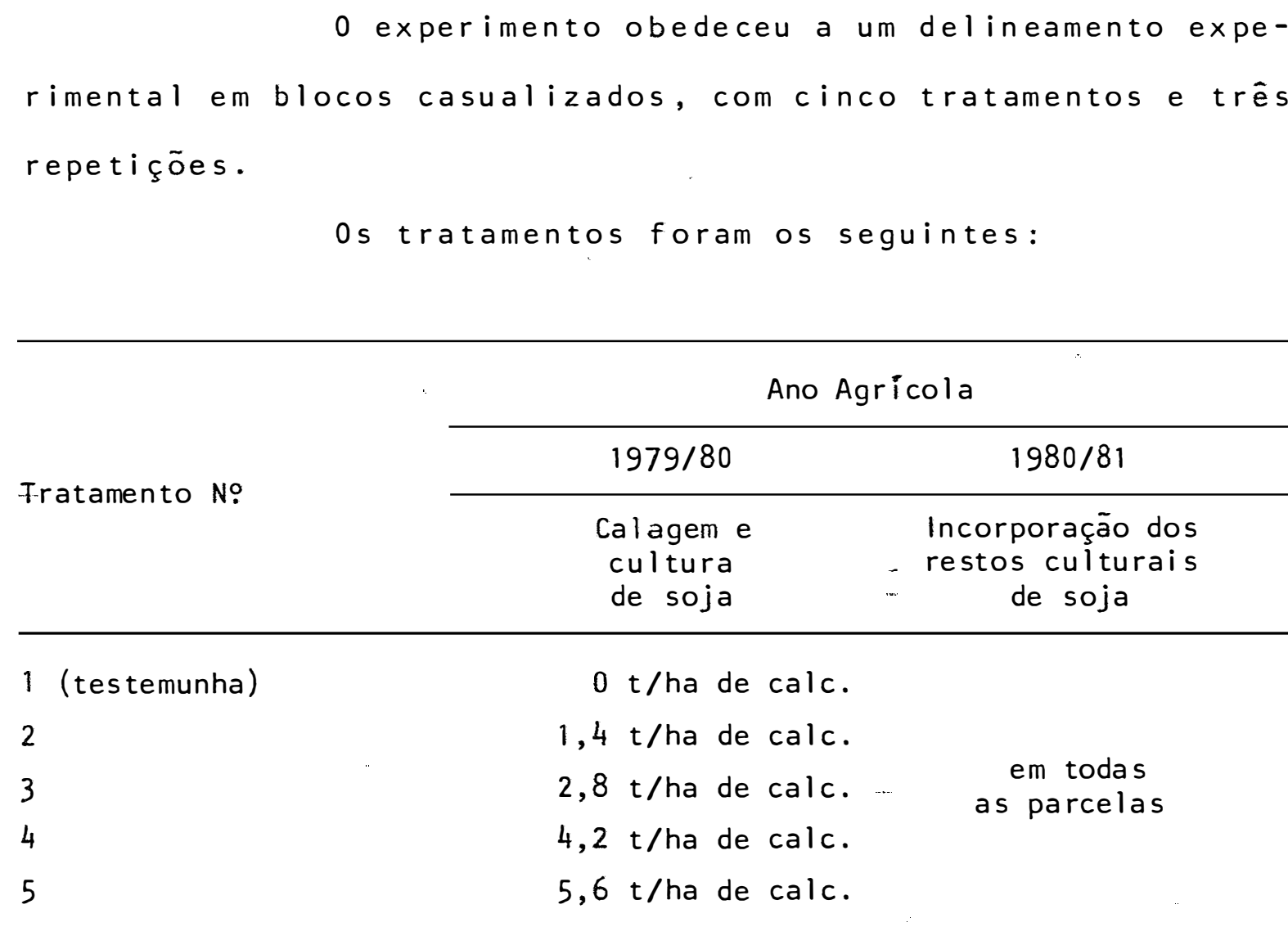

\subsection{Delimitação das parcelas}

As parcelas experimentais foram delimitadas uma semana antes da calagem, ficando cada uma, com as dimensões de $10 \times 30 \mathrm{~m}\left(300 \mathrm{~m}^{2}\right)$. 


\subsection{Calagem}

Um calcário dolomítico, cujo PRNT calculado foi de $61 \%$, foi aplicado em $22 / 10 / 79$ a lanço, manualmente e incor porado a uma profundidade média de $20 \mathrm{~cm}$, com aração, através de arado tipo reversivel. Cerca de 15 dias após foi feita uma gradagem. As doses de calcário aplicadas foram calculadas mul tiplicando-se a quantidade de calcário necessária para elevar - pH a 6,5 pelo método de CATANI e GALLO (1955), pelos seguin tes fatores: $0 ; 0,5 ; 1,0 ; 1,5$ e 2,0 .

- No ano agrícola 79/80, tais parcelas foram cul tivadas com soja, usando-se como adubação básica $290 \mathrm{~kg}$ de $\mathrm{P}_{2} \mathrm{O}_{5}$ e $250 \mathrm{~kg}$ de $\mathrm{K}_{2} \mathrm{O} / \mathrm{ha}$, nas formas, respectivamente, de superfosfato triplo $\left(42 \% \mathrm{P}_{2}{ }_{5}\right)$ e cloreto de potássio $\left(60 \% \mathrm{~K}_{2} 0\right)$.

\subsection{Produção, CARACTERÍsticas QUİMICAS E INCORPORAÇÃO DOS RESIDDUOS VEGETAIS}

Prōxima à colheita dos grãos, cuja produçãofoi cerca de $900 \mathrm{~kg} / \mathrm{ha}$, procedeu a uma amostragem de plantas para avaliação da massa dos restos culturais.

Em cada.parcela foram tomadas a parte aérea de 10 plantas, as quais após a remoção das vagens, foram secas em estú fa a $70^{\circ} \mathrm{C}$ até peso constante.

o material seco foi moído e analisado quanto 
aos teores de carbono (VETTORI, 1969), nitrogênio, fósforo, cälcio e magnésio (SARRUGE e HAAG, 1974), cujos resultados são apresentados na tabela 2 .

TABELA 2 - Caracteristicas quimicas dos restos de cultura de soja incorpo rados ao solo.

\begin{tabular}{|c|c|c|c|c|c|c|}
\hline \multicolumn{2}{|c|}{$\%$} & \multirow[b]{2}{*}{$C / N$} & \multicolumn{4}{|c|}{$\%$} \\
\hline C & $N$-total & & $P$ & K & $\mathrm{Ca}$ & $\mathrm{Mg}$ \\
\hline 45,6 & 1,90 & 24 & 0,08 & 2,26 & 0,65 & 0,48 \\
\hline
\end{tabular}

A produção de matéria seca da cultura de soja, massa da parte aérea, foi de 1,9 t/ha, não havendo diferen ças significativas entre tratamentos.

Tais restos culturais foram incorporados ao so lo em 01/06/80, através de arado tipo reversível, a uma pro fundidade média de $20 \mathrm{~cm}$.

\subsection{Amostragem de solo}

No dia $21 / 08 / 80 \quad(300$ dias apōs a calagem e 80 dias apōs a incorporação dos restos culturais), tomaram-se amostras de terra em cada uma das parcelas experimentais. Tais 
amostras foram constituidas de dez amostras simples, tomadas ao acaso no interior de cada parcela útil (156 $\left.\mathrm{m}^{2}\right)$ e nas profundidades de 0-20 cm e 20-40 cm, as quais foram acondicionadas em sacos plásticos e imediatamente levadas para labora tōrio.

\subsection{ANÁLISES DE SOLO}

\subsubsection{DETERMinAÇÃo da UMIDADE ATUAL}

Cerca de 50 g de cada amostra de terra foram colocadas em latas de alumínio, previamente taradas, e, apös pesagem, foram levadas para estufa e ai mantidas a 100-1100C por 24 horas. Após esse período, foram deixadas esfriar em des secador e novamente pesadas. Por diferenças de massa, calculou-se a umidade atual.

3.7.2. DETERMINAÇÃO DO PH

0 pH em àgua foi determinado na TFSA, seguindo-se o mëtodo de Catani et alii (1955), conforme descrito em MELLO et alii (1965), usando-se a relação solo : āgua de 1:2,5. 


\subsubsection{DETERMinAÇÃo de ALUMİNio, POTÁSSIO, CĀLCIO + MAGNÉSIO TROCÁVEIS E FŌSFORO SOLŪVEL}

O $\mathrm{Al}^{3+}, \mathrm{K}^{+}, \mathrm{Ca}^{2+}+\mathrm{Mg}^{2+}$ trocāveis e O P solúvel foram determinados de acordo com a metodologia descrita em VAN RAIJ e ZULLO (1977).

\subsubsection{DETERMINAÇÃO DA CAPACIDADE DE TROCA DE CÁTIONS EFETIVA (CTC)}

A CTC efetiva foi determinada indiretamente co mo se faz rotineiramente pela soma dos principais cátions tro cáveis $\left(\mathrm{Ca}^{2+}, \mathrm{Mg}^{2+}, \mathrm{K}^{+}, \mathrm{Al}^{3+} \mathrm{e} \mathrm{H}^{+}\right)$.

\subsubsection{DETERMINAÇÃo DA PORCENTAGEM DE SATURAÇÃo EM BASES ( $V \%)$}

A V\% foi determinada em função da CTC efetiva e da soma de bases trocáveis, usando-se a seguinte förmula:

$$
\mathrm{V} \%=\frac{\mathrm{Ca}^{2+}+\mathrm{Mg}^{2+}+\mathrm{K}^{+}}{\mathrm{CTC}} \times 100
$$




\subsubsection{EXTRAÇÃo DOS ÁCIDOS HÜMICOS E FÚlvicos}

A extração dos àcidos húmicos e fülvicos foi feita de acordo com o método descrito em TOLEDo (1973), usando-se uma solução de hidrōxido de sódio $0,5 \mathrm{~N}$ como extrator, po. rēm, sem utilizar o pré-tratamento com solução de ácido clorí drico.

Para tanto, $20 \mathrm{~g}$ de terra, previamente moídos e passados em peneira de $0,5 \mathrm{~mm}$ de diâmetro, foram colocados em tubos de centrifuga com capacidade de $150 \mathrm{ml}$, aos quais adicionaram-se $80 \mathrm{ml}$ da solução de $\mathrm{NaOH} 0,5 \mathrm{~N}$ e levados para agitar intermitentemente em agitador horizontal por duas horas. Findo tal período, seguiu-se centrifugação por 20 minutos a $3.000 \mathrm{rpm}$.

Toda operação foi repetida até obter um sobre nadante bem claro e o resíduo de terra foi neutralizado com solução de ácido sulfúrico $0,2 \mathrm{~N}$ e levado para secar em estufa a $60-700 \mathrm{C}$.

A separação dos ácidos húmicos e fülvicos foi feita tomando-se uma alíquota de $100 \mathrm{ml}$ do extrato, à qual adicionaram-se $\mathrm{H}_{2} \mathrm{SO}_{4}$ concentrado até obter pH 2, 0 , seguindo-se repouso por duas horas e centrifugação por 10 minutos $6.000 \mathrm{rpm}$. 


\subsubsection{DOSAGEM DE CARBONO}

\subsubsection{Carbono orgânico total}

o carbono orgânico total foi determinado pelo método de Tiurim (oxidação por via ümida), conforme descrito em VETTORI (1969).

\subsubsection{Carbono nas fraçōes hümicas}

A dosagem de carbono nas frações hümicas foi feita, usando-se a mesma metodologia utilizada para a determi nação do carbono orgânico total (método de Tiurim), conforme descrito em VETTORI (1969), tomando-se, para tanto, $10 \mathrm{ml}$ do extrato de ácidos húmicos, $20 \mathrm{ml}$ do extrato de ácidos fúlvi$\cos$ e $1,0 \mathrm{~g}$ do residuo.

\subsection{8, DOSAGEM DE NITROGÊNIO}

3.7.8.1. Nitrogénio total no solo

$0 N$ - total foi determinado pelo método microkjeldahl, conforme descrito em MELO (1977). 


\subsubsection{Nitrogênio total nas frações hümicas}

o N-total nas fraçōes húmicas foi determinado usando-se a mesma metodologia utilizada na dosagem de $N$-total no solo (método microkjeldahl) conforme descrito em MELO (1977), tomando-se, para tanto, $10 \mathrm{ml}$ do extrato de äcidos hümicos, $20 \mathrm{ml}$ do extrato de äcidos fülvicos e $1,0 \mathrm{~g}$ do residuo. 


\title{
4. RESULTADOS E DISCUSSÃO
}

\subsection{UMIDADE ATUAL}

\begin{abstract}
Os valores de umidade atual (Tabela 3 ), nas duas profundidades analisadas, não apresentaram diferenças sig nificativas estatisticamente, pelo teste $F$, em função dos tra tamentos. Cabe ressaltar, por outro lado, que os valores de $\underline{u}$ midade obtidos na profundidade de $20-40 \mathrm{~cm}$ foram ligeiramente superiores aos obtidos na profundidade de $0-20 \mathrm{~cm}$, o que pode ser em parte atribuido ao fato das camadas mais superiores es tarem sujeitas a maiores evaporações.
\end{abstract}

\section{2. $\mathrm{PH}$}

Os valores pH obtidos na profundidade de
$0-20 \mathrm{~cm}$ foram significativamente diferentes em função dos tra


tamentos, enquanto que na profundidade de $20-40 \mathrm{~cm}$ não se verificou diferença significativa (Tabela 3 ). Os resultados evi denciam que embora tendo havido efeito significativo de trata mento para a profundidade de $0-20 \mathrm{~cm}$, os valores pH ficaram pröximos de 6,0 e, em nenhum tratamento, atingiramovalor 6,5 como visa o método de cālculo das doses de calcārio aqui empregado. Os valores pH na profundidade de $20-40 \mathrm{~cm}$ foram $1 \mathrm{i}-$ gei ramente inferiores a aqueles obtidos na profundidade de 0-20 cm e não diferiram estatisticamente da testemunha; tal resultado evidencia que os métodos tradicionais de aplicação de calcário (incorporação na camada arável) não apresentaram eficācia na correção do pH nas camadas mais profundas do solo estudado.

\subsection{Alumínio trocável}

os valores de $\mathrm{Al}^{3+}$ trocável (Tabela 3 ), na pró fundidade de $0-20 \mathrm{~cm}$, apresentaram diferenças significativas em função dos tratamentos, enquanto que na profundidade de 20-40 cm, evidenciaram uma ligeira diminuição nos teores nos tratamentos com calcário, sem, contudo, diferir estatisticamen te da testemunha. Na camada de 0-20 cm a dose de calcārio de $1,4 \mathrm{t} / \mathrm{ha}$ foi suficiente para eliminar praticamente todo o $A 1^{3+}$ trocável até a época da amostragem, ao passo que na profundidade de $20-40 \mathrm{~cm}$, nem a maior dose de calcário utilizada $(5,6 \mathrm{t} / \mathrm{ha})$ foi eficiente para uma completa neutralização. VAN 
RAlJ et alii (1977), aplicando 4,6 t calcärio/ha, verificaram, dois anos após, teores de Al iguais a zero, enquanto que ANJos et alii (1981) constataram que, para doses de calcário de 10 e 20 t/ha, 48 meses apōs, O $\mathrm{Al}^{3+}$ ainda se mantinha em niveis não töxicos.

\subsection{CÁlCIO + MAgnésio TROCÁveis}

$$
0 s \text { teores de } \mathrm{Ca}^{2+}+M g^{2+} \text { trocáveis (Tabela } 3 \text { ) }
$$

aumentaram nas duas profundidades analisadas nas parcelas que receberam calcário, embora não se tenha encontrado valores es tatisticamente diferentes da testemunha. Na profundidade de 20-40 cm os teores foram menores que de $0-20 \mathrm{~cm}$ para todos os tratamentos o que já era de se esperar uma vez que o calcário foi incorporado superficialmente, não eliminando, portanto, todo $\mathrm{Al}^{3+}$ trocável do complexo de troca de $20-40 \mathrm{~cm}$. Resultados semelhantes foram encontrados por VAN RAIJ et alii (1977) em solos de cerrado onde, durante dois anos após a calagem $(4,5 \mathrm{t} / \mathrm{ha})$, constataram teores de $\mathrm{Ca}^{2+}+\mathrm{Mg}^{2+}$ variando entre 3,0 e $3,8 \mathrm{~m}$.eq/100 g terra. ANJos et alii (1981) encontraram teores de $\mathrm{Ca}^{2+}+\mathrm{Mg}^{2+}$ crescentes até 10 meses após cala gem, ëpoca essa que consideraram de maior solubilidade do cal cário. 


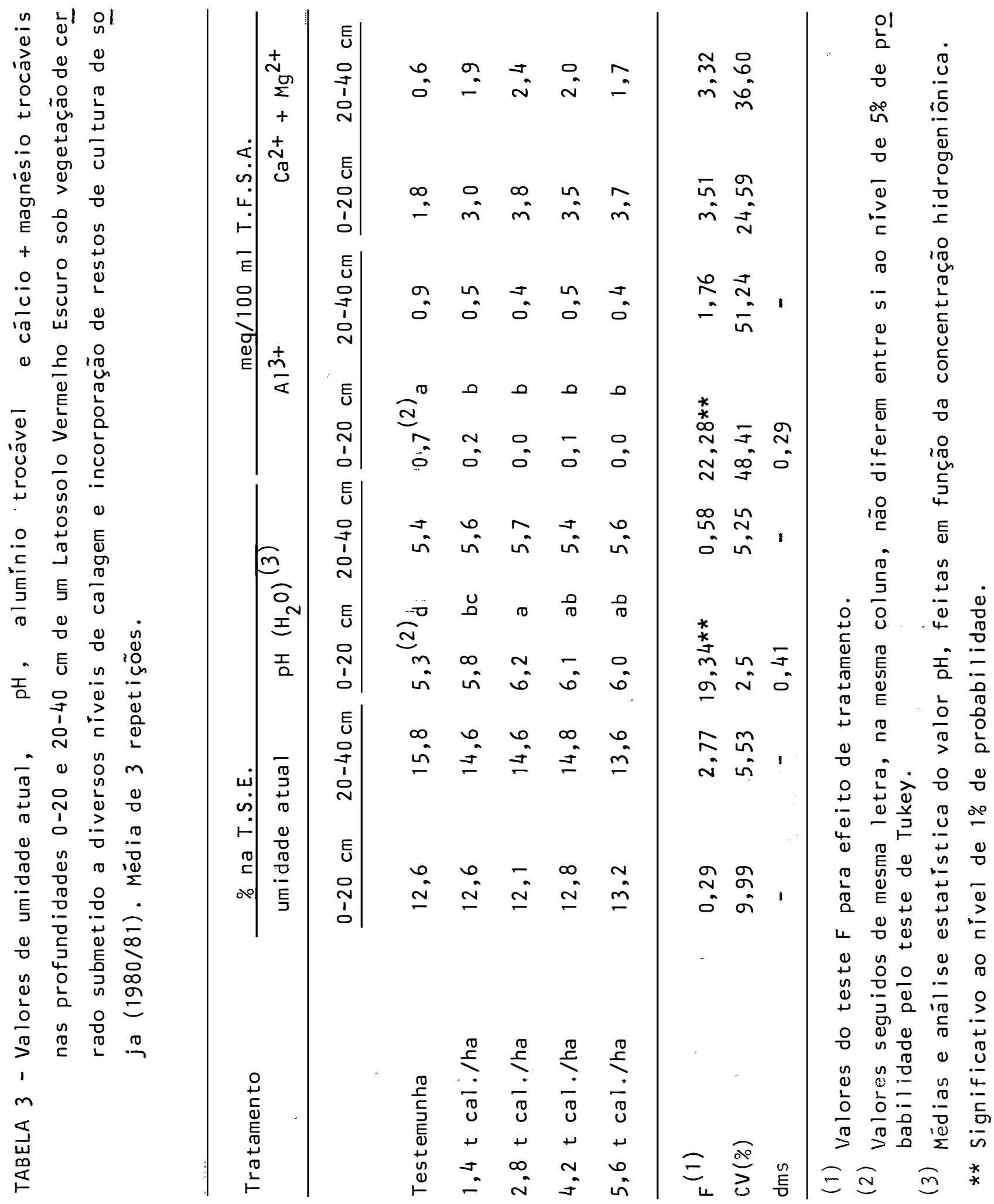




\title{
4.5. Potássio trocāvel
}

\begin{abstract}
Os teores de $\mathrm{K}^{+}$trocāvel (Tabela 4) na camada de 0-20 cm foram superiores aos da camada de 20-40 cm. Tais re sultados pareceram bastante lógicos visto que, tanto a adubação bãsica $(250 \mathrm{~kg} \mathrm{~K} 20 / \mathrm{ha})$ como a incorporação dos restos cul turais, foram feitos na camada arável $(0-20 \mathrm{~cm})$. Nas duas pro fundidades estudadas os teores de $\mathrm{K}^{+}$trocável apresentaram tendências de diminuições com o aumento das doses de calcáriO. MIELNICZUK e ANGHINONI (1976) verificaram que doses anuais médias de $40 \mathrm{~kg} / \mathrm{ha}$ de $\mathrm{K}_{2} 0 \mathrm{em}$ periodo de 6 anos, aumenta ram os teores de potássio de 58 para 78 ppm em lavouras de so ja.
\end{abstract}

\subsection{FósForo SOLŪVEL}

Os teores de fósforo solūvel (Tabela 4), nas duas profundidades analisadas, não apresentaram diferenças entre os tratamentos com calcārio e a testemunha.

Por outro íado, verifica-se que os teores de fósforo na camada de $0-20 \mathrm{~cm}$ foram em média o dobro dos teores de 20-40 cm, o que pode ser explicado pelo fato da adubação e a incorporação dos restos culturais terem sido feitos superficialmente. Além disso, deve-se considerar a baixa difü são do fósforo no solo e a pequena quantidade adicionada $(1,52 \mathrm{~kg}$ de P/hal na forma de restos de cultura. 


\title{
4.7. CTC EFETIVA
}

\begin{abstract}
Os valores de CTC efetiva (Tabela 4), nas
duas profundidades estudadas, não apresentaram diferenças sig nificativas estatisticamente entre tratamentos com calcário e testemunha, embora todos os tratamentos com calagem tenham apresentado valores ligeiramente superiores à testemunha.

Na profundidade de $0-20 \mathrm{~cm}$ os valores mëdios de CTC foram cerca de $30 \%$ maiores que os da camada de $20-40 \mathrm{~cm}$, o que em parte pode ser atribuido aos mesmos motivos apresentados para potássio, fósforo e cālcio +magnésio.
\end{abstract}

\subsection{Porcentagem de saturação em bases ( $v \%$ )}

os valores de $V \%$ (Tabela 4 ), nos tratamentos que receberam calcārio,foram estatisticamente diferentes da testemunha ao nivel de $1 \%$ de probabilidade na camada de 0-20 cm. Embora os valores não apresentem diferenças entre os tratamentos que receberam calcārio, todos foram diferentes da testemunha, indicando, assim, que a porcentagem de saturação em bases responde bem à calagem. LAROCHE (1967) encontrou valores de $V \%$ crescentes com aumentos de doses de carbonatos em experimento de vasos. 


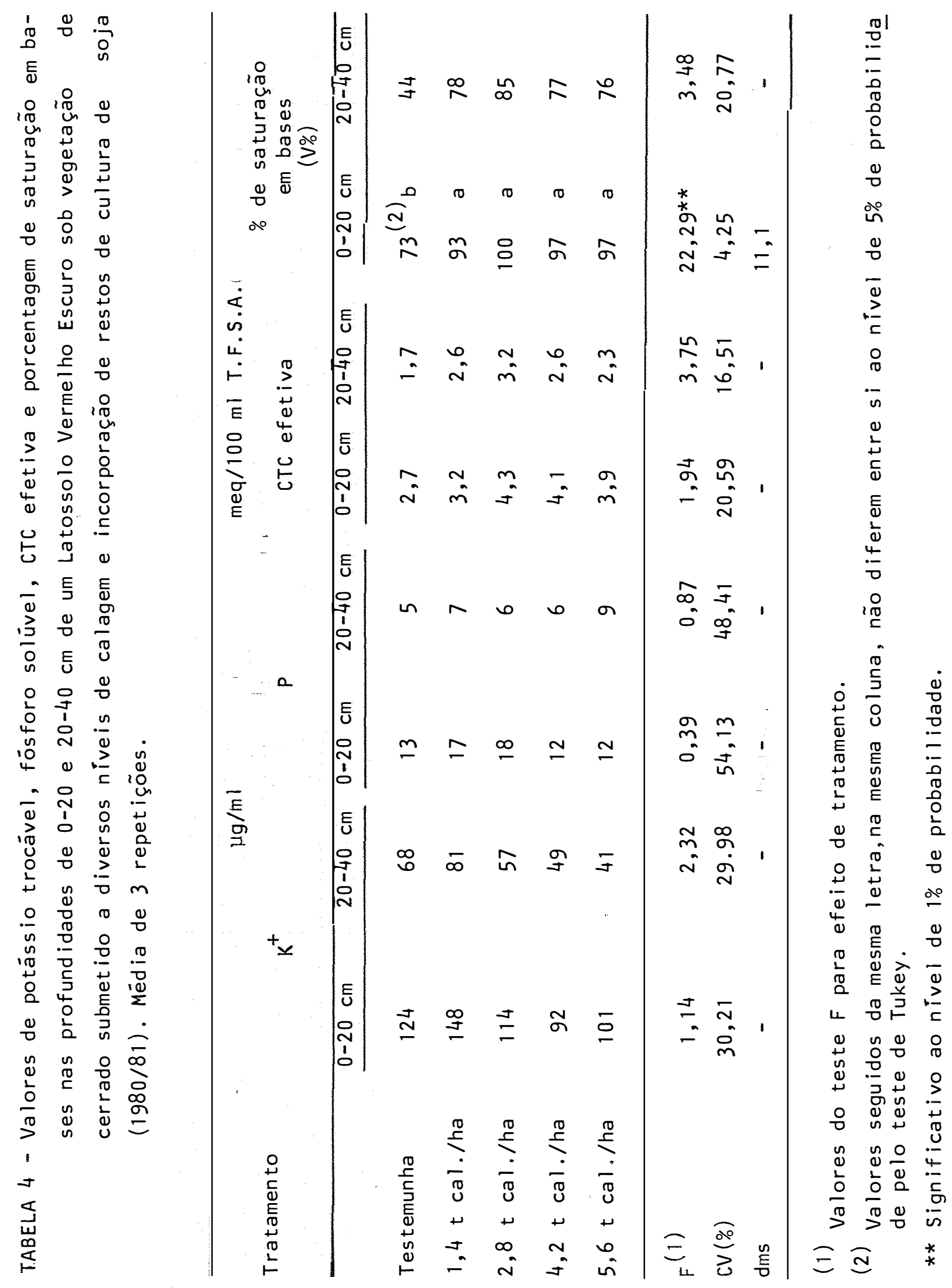


$\mathrm{Na}$ profundidade de $20-40 \mathrm{~cm}$, os valores de $\mathrm{V} \%$, nos tratamentos com calcário, foram superiores ao da testemunha, sem, contudo, diferir dessa estatisticamente. Por outro lado, verifica-se que, no geral, os valores de V\% na camada de $0-20 \mathrm{~cm}$ foram maiores que na de $20-40 \mathrm{~cm}$.

\subsection{Carbono nas frações da matéria orgânica}

Os teores de carbono orgânico total, carbono nos ácidos húmicos, carbono nos ácidos fülvicos e carbono nas huminas são apresentados na Tabela 5 e Figid 1.

o carbono orgânico total não apresentou diferenças significativas entre os tratamentos. No geral, em todos os tratamentos, os valores de carbono orgânico total na camada de 0-20 cm foram, em média, cerca de $25 \%$ superiores aos da camada de $20-40 \mathrm{~cm}$. A quase ausência de variação do carbono orgânico em função dos tratamentos confirma os resultados de ANJOS et alii (1981).

Quanto ao carbono nas frações húmicas, veriłficou-se um comportamento semelhante ao carbono orgânico total, ou seja, praticamente não houve diferenças nos teores em função dos tratamentos e, na profundidade de $0-20 \mathrm{~cm}$, os valores foram sempre superiores aos da profundidade de $20-40 \mathrm{~cm}$. A dis tribuição do carbono nas frações hümicas estudadas confirmam os resultados encontrados por NASCIMENTO e MELO (1981), On 
de o carbono aparece na seguinte seqüência:

huminas ou residuo > àcidos fūlvicos > ácidos húmicos. POLO et

alii (1978a) encontraram em solos sob floresta mais ácidos hú micos que fúlvicos elevados teores de huminas.

A respeito da distribuição relativa do carbono nas frações estudadas (Figura 1), constatou-se que, em média para as duas profundidades, os teores de carbono nos ácidos húmicos representaram cerca de $4 \%$ do carbono orgânico total, enquanto que nos ácidos fülvicos e huminas, os teores de carbono, em relação ao carbono orgânico total, foram da ordem de 25 e $58 \%$, respectivamente.

\subsection{Nitrogênio nas frações da matéria orgânica}

os teores de N-total no solo, nos àcidos húmicos, nos ácidos fúlvicos e nas huminas são apresentados na Tá bela 6 e Figura 2 .

Os teores de $\mathrm{N}$-total no solo não apresentaram diferenças significativas em função dos tratamentos nas duas profundidades analisadas, sendo que na profundidadede $0-20 \mathrm{~cm}$, os valores foram em média cerca de $22 \%$ maiores que os da profundidade de $20-40 \mathrm{~cm}$.

os resultados para $N$-total no solo evidenciam um comportamento semelhante ao encontrado para carbono orgâni co total, o que já era de se esperar, uma vez que a quase to 







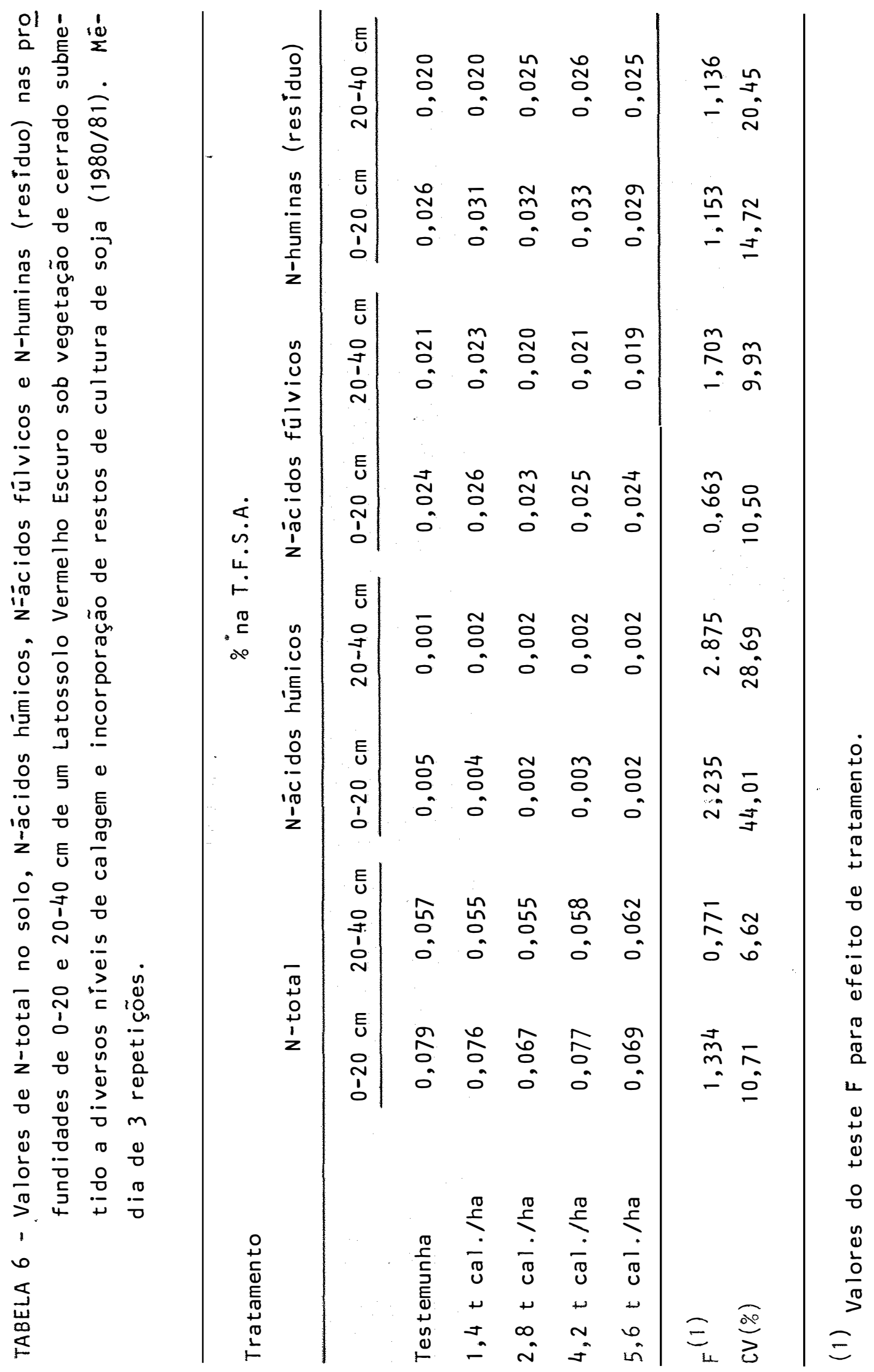




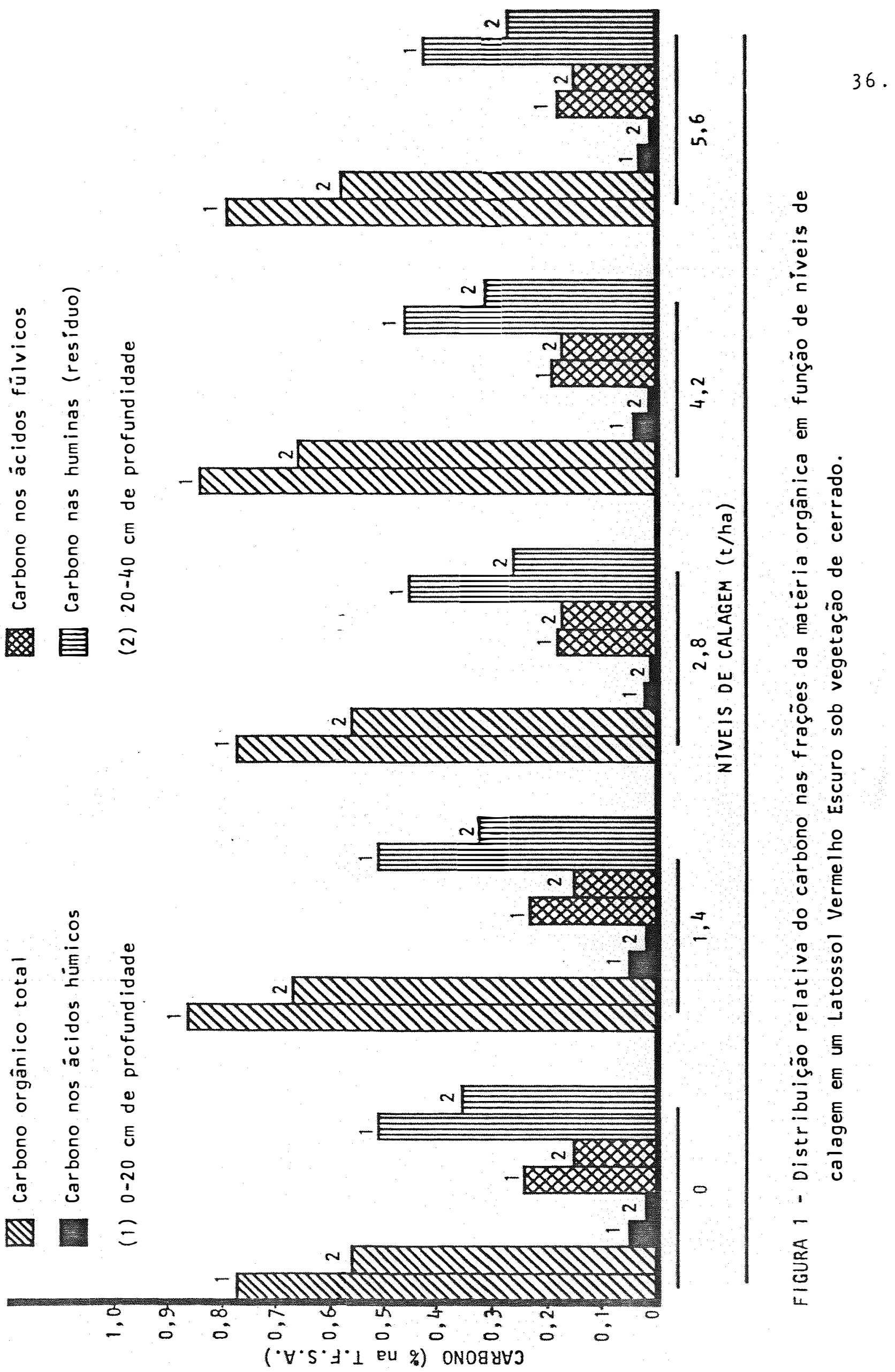



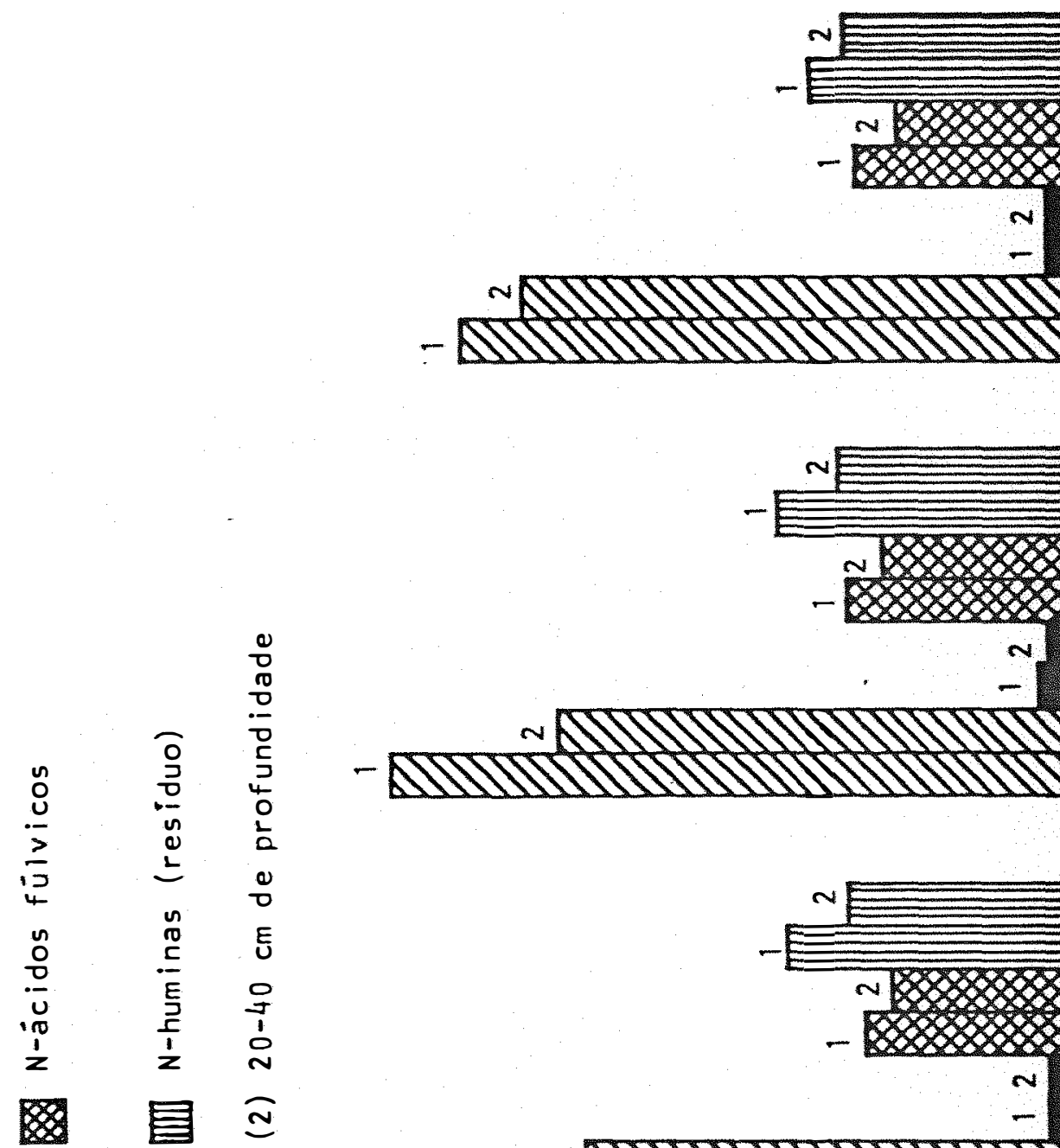

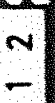

37.
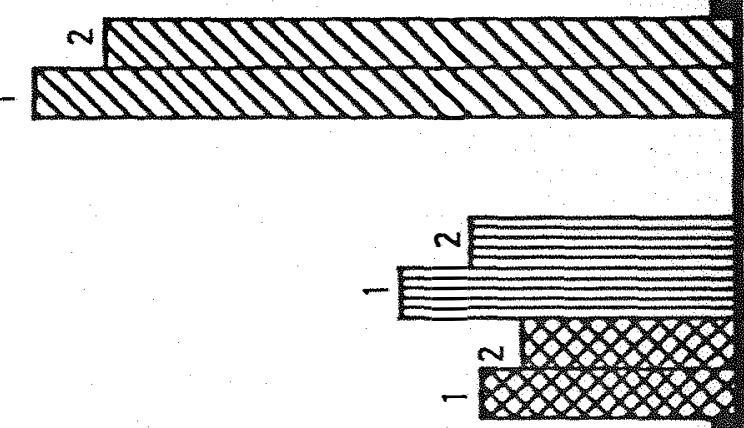

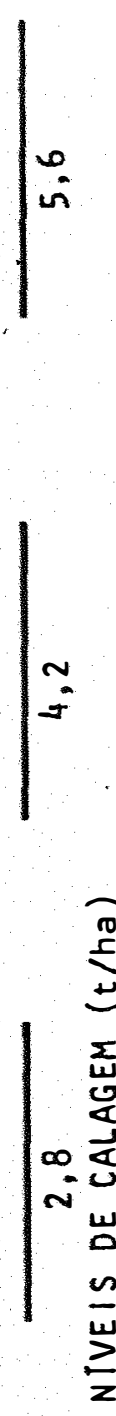

$\frac{n}{2}$

¿

10

范
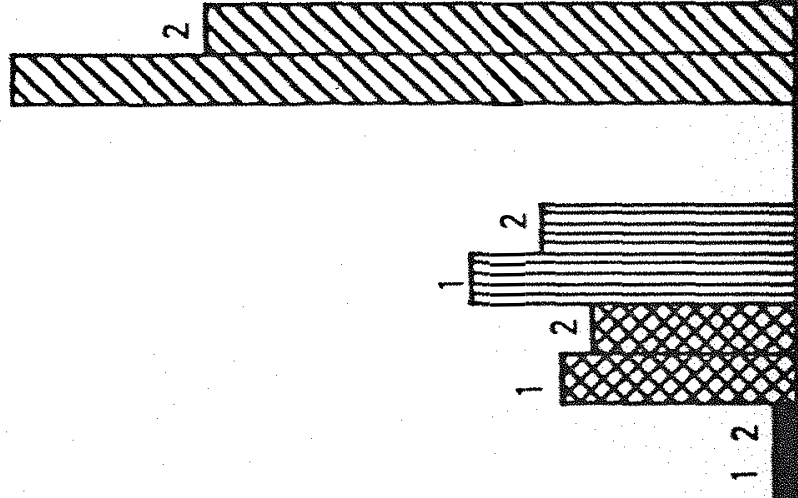

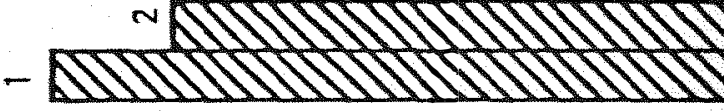

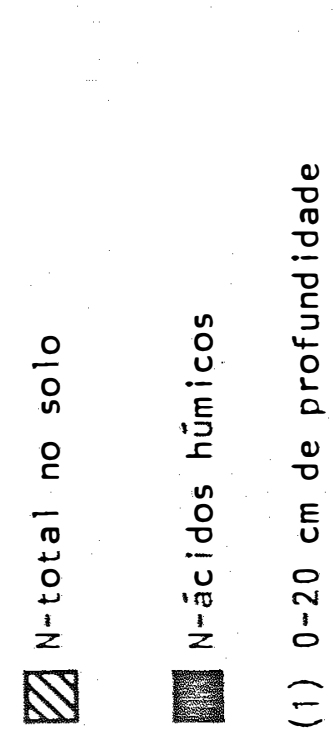

- गा1ा।ा1
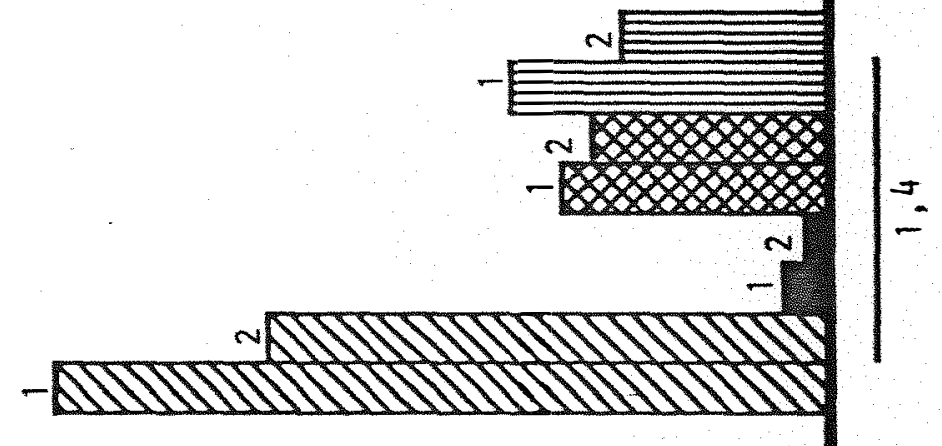

.
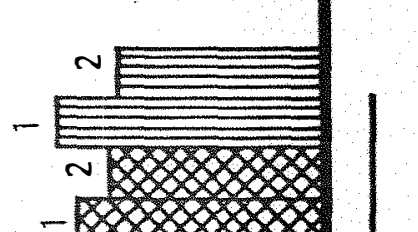

E

$\begin{array}{cc}0 & 0 \\ 0 & 0 \\ 0 & 0 \\ 1 & 2 \\ 0 & 0 \\ 0 & 0 \\ 0 & 0\end{array}$

$\begin{array}{lll}1 & 0 \\ 0 & 0 & 0 \\ 1 & 0 & 0\end{array}$

$\therefore 2$

is 10

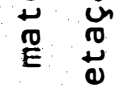

\%

告 0

i 0

每

ᄃ U

을 옴

ช

닌

$\therefore>$

응

$\div \quad$

\begin{tabular}{l}
0 \\
$\geq$ \\
$\geq$ \\
\hdashline
\end{tabular}

듬

O E

䓿

늘

는

on

$\because \frac{0}{0}$

N
$\frac{5}{5}$
$\frac{0}{3}$
$\frac{0}{4}$

$\div$

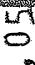

$0^{\circ}$

$\circ$

( $\forall^{\circ} S^{*} J \cdot 1$ eu \%) OINJMOYIIN 
talidade do nitrogênio do solo se encontra na matéria orgânica.

Com relação ao N-total nas frações hümicas estudadas, verificou-se um comportamento semelhante ao do $\mathrm{N}$-total no solo, ou seja, não houve diferença significativa dos teores em função dos tratamentos. Os valores encontrados na profundidade de $0-20 \mathrm{~cm}$ foram, no geral, superiores aos da pró fundidade de 20-40 cm, exceto para o caso dos ácidos húmicos, nos tratamentos que receberam 2,8 e 5,6 t de calcário/ha.

Quanto à distribuição relativa do $N$-total nas frações hümicas estudadàs (Figura 2), verifica-se que,em média para as duas profundidades, os valores de $\mathrm{N}$-total nos áci dos húmicos representaram cerca de $4 \%$ do N-total do solo, enquanto que nos ácidos fúlvicos e huminas os teores de N-total foram da ordem de 32 e $41 \%$, respectivamente, em relação ao $\mathrm{N}$-total do solo.

\subsection{ReLAÇÃo C/N NAS FRAções da MATÉRIA ORGÂnica}

Os valores da relação $C / N$ no solo, nos ácidos húmicos, nos àcidos fúlvicos e nas huminas são apresentados na Tabela 7 e Figura 3 .

A relação C/N no solo, cujos valores estão entre 9,5 e 11,4, praticamente não apresentou variação em função dos tratamentos e da profundidade.

Por outro lado, a relação C/N nos äcidos hümi- 
39.

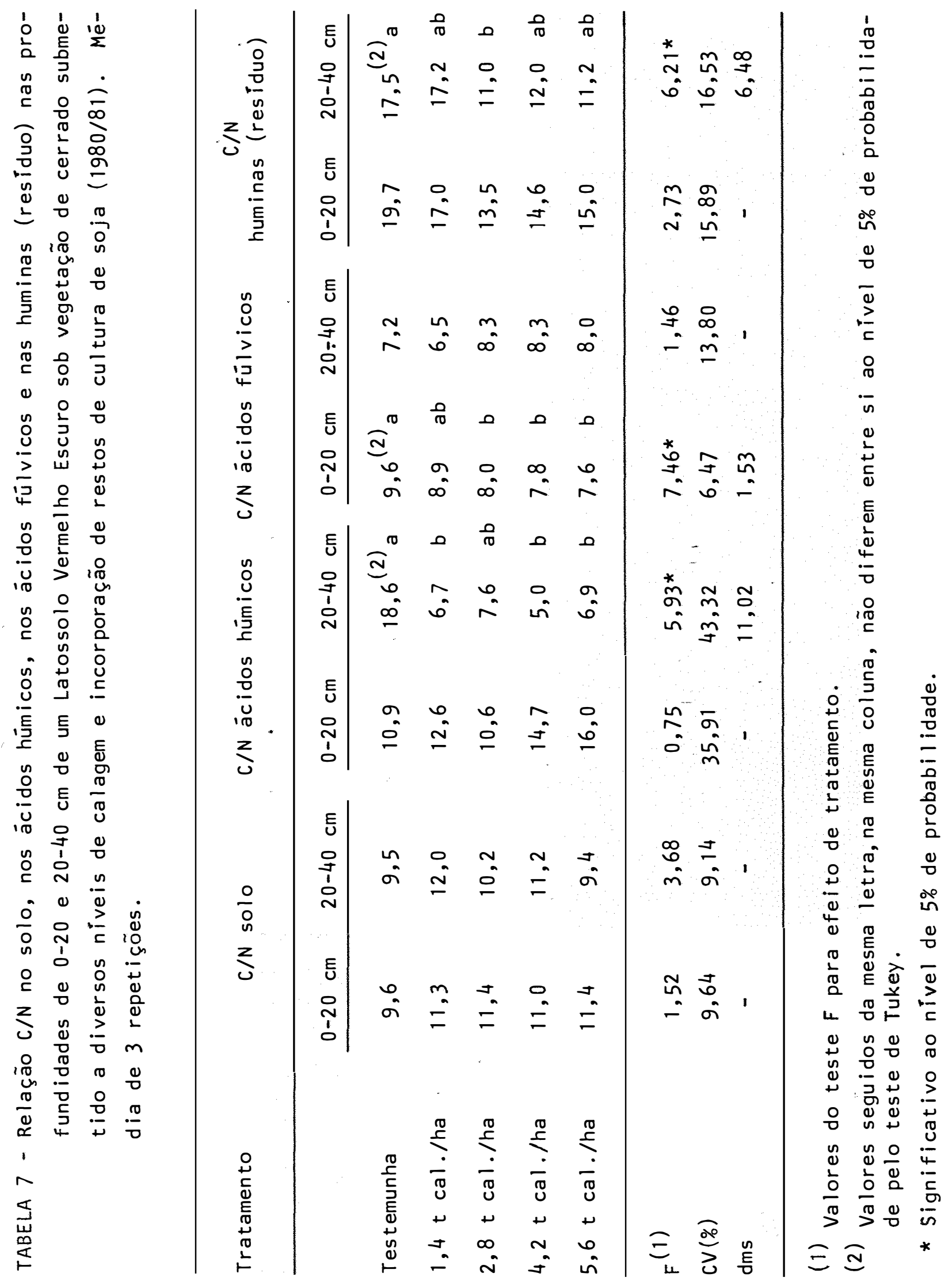



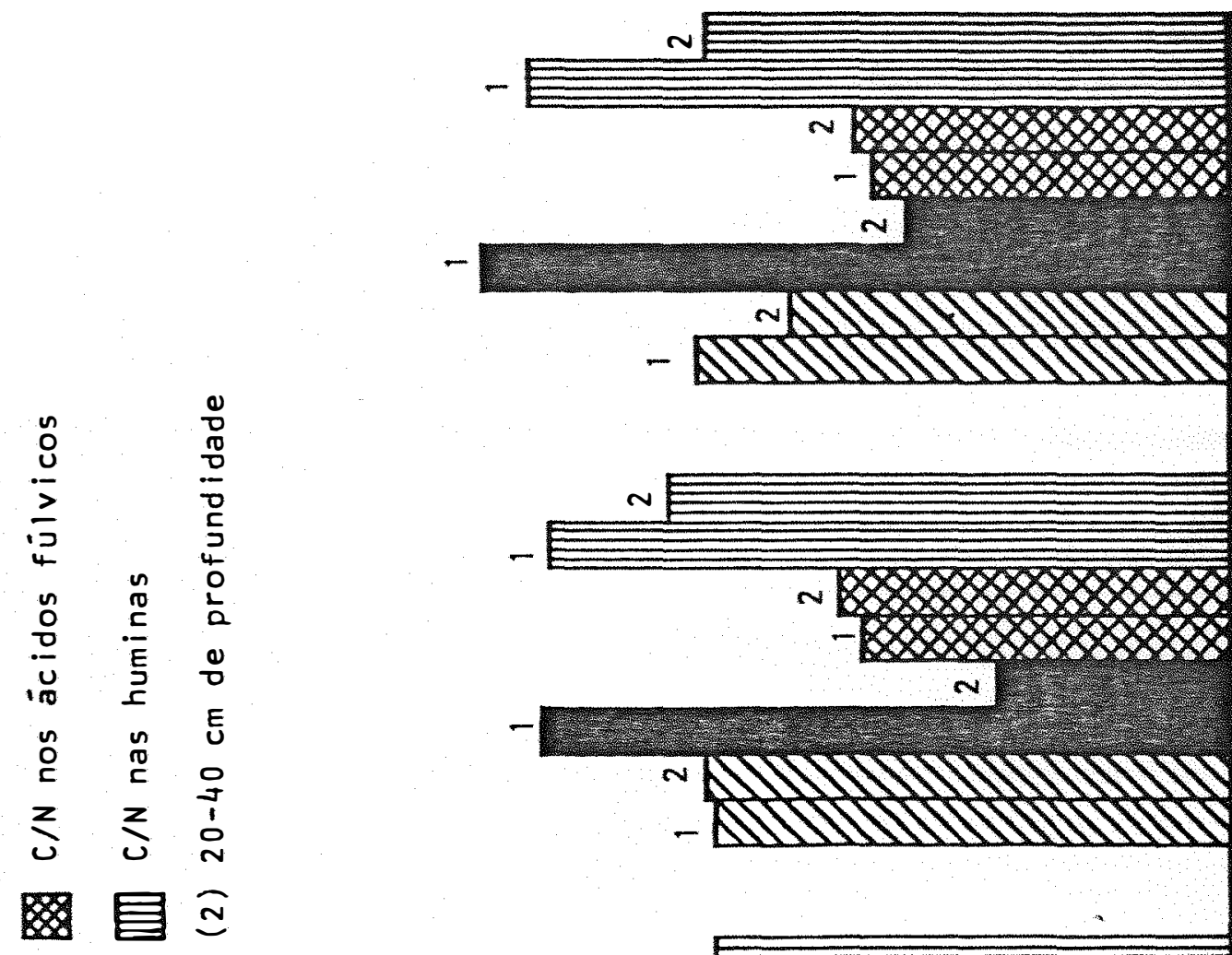

N
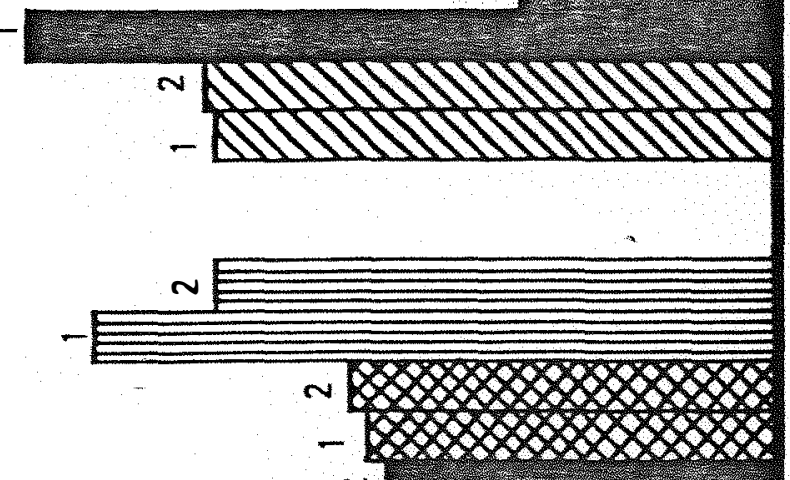

N

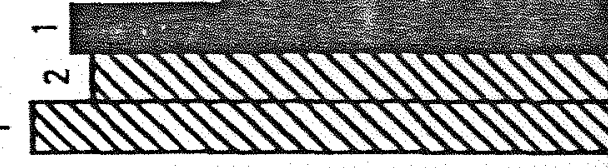

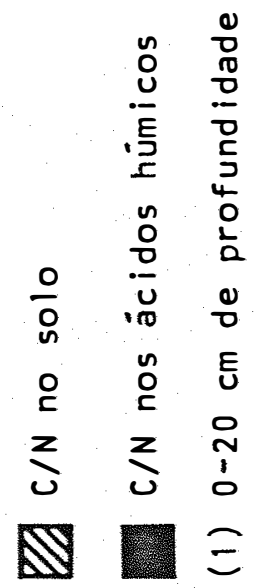
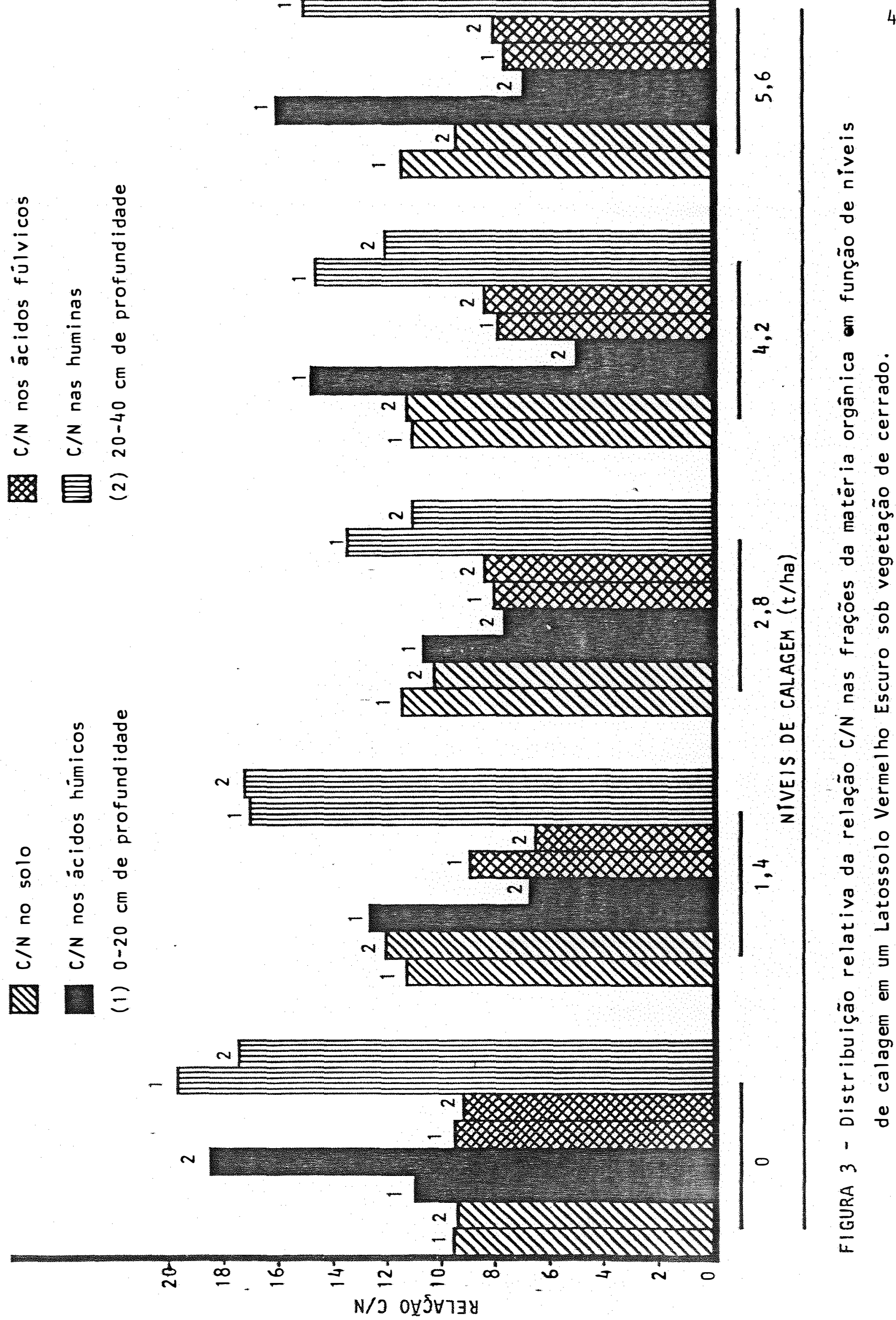

40. 
cos apresentou no geral, valores maiores na profundidade de $0-20 \mathrm{~cm}$.

Nos àcidos fūlvicos, a relação $C / N$ vàriou muito pouco em função tanto de tratamento, como da profundidade, enquanto que nas huminas a relação $C / N$ apresentou tendèncias de decréscimo com o aumento das doses de calcārio nas duas profundidades. 


\section{CONCLUSÕES}

Dos resultados obtidos podem ser tiradas as se guintes conclusões:

1. A incorporação do calcário na camada arável não apresen tou eficácia na correção do $\mathrm{pH}$ nem na neutralização do $\mathrm{A}^{3+}$ trocável nas camadas mais profundas do solo estudado.

2. Nas duas profundidades estudadas houve tendência de diminuição nos teores de $\mathrm{K}^{+}$trocāvel com o aumento das doses de calcärio.

3. A calagem não afetou de modo significativo a distribuição do carbono e do nitrogênio nas diferentes fraçōes da matéria orgânica, porém houve tendência de diminuição da relação $C / N$ das huminas. 
4. A distribuição do carbono e do nitrogênio nas fraçōes hūmí cas estudadas obedeceu à seguinte seqüência:

huminas > àcidos fūlvicos >ảcidos húmicos. 


\section{LITERATURA CITADA}

ABRUNA, F.; J. VICENTE-CHANDLER e R.W. PEARSON, 1964. Effects of liming on yields in composition of hearvily fertilized grasses and on soils properties under humid tropical conditions. Soil Sci. Soc. of Am. Proc., Madison, 28(5): $657-661$.

AKINOLA, A.A. e R.B. COREY, 1973. The relationship between soil pH, organic matter, available phosphorus exchangeable potassium, calcium, magnesium and nine elements in the maize tissue. Soil Sci., Baltimore, 115(3): 367-371.

ALMEIDA, D.L.; R.C. SALEK; M.I.S.D. RIBEIRO e G.A. SANTOS, 1981. Efeito de adubos orgànicos em culturas de tomateiro no municipio de Vassouras. In: XVIII Congresso Brasileiro de Ciència do Solo, Salvador. Resumos. P.57. 
ALMENDROS, 0. e A. POLO, 1980. Contribución al estudio de los compuestos húmicos de los restos vegetales y de la materia orgānica en diversos suelos bajo encina. Agrochimica, Pisa, 5-6(24): $369-380$.

ANDREUX, F. e S.P. BECERRA, 1975. Fracionamiento y caracterización del material húmico en algunos suelos de sabana de la Orinoquia Colombiana. Turrialba, Turrialba, 2(25): 191198 .

ANJOS, J.T.; M. PUNDEK; G. TASSINARI e S.S. GRIMM, 1981. Efeito da calagem e da adubação fosfatada sobre algumas propriedades químicas de um Combinado húmico distrófico cultivado com milho. R. bras. Ci. Solo, Campinas, 5: 50-54.

BARBIERI, L.C.S.; W.J. MELO e P. ZANETTI NETO, 1979. Efeitos de alguns adubos verdes sobre formas de carbono e de nitrogênio de um Latossolo Vermelho Amarelo - fase arenosa. In: XVII Congresso Brasileiro de Ciência do Solo, Manaus. Resumos. p. 43 .

BLACK, C.A., 1957. Soil-plants relationships. New York, John Wiley. p.128-158.

BLOOM, P.R.; M.B. MCBRIDE, e R.M. WEAVER, 1979. Aluminium organic matter in Acid Soils. Soil Sci. Soc. Am. J., Madison, 43: 488-493.

CATAN I, R.A. e J.R. GALLO, 1955. Avaliação da exigência em calcário dos solos do Estado de São Paulo, mediante correla ção entre o pH e a porcentagem de saturação de bases. Revista de Agricultura, Piracicaba, 30(1,2,3): 49-60. 
CATANI, R.A. e A.0. JACINTO, 1974. Anālise química para avaliar a fertilidade do solo. Piracicaba, E.S.A. "Luiz de Queiroz", 54p. (Bol. Téc. Cient. n? 37)

COLEMAN, N.T.; E.J. KAMPRATH e S.B. WEED, 1958. Liming.

Advances in Agronomy, New York, 10:475-522.

DABIN, B., 1976. Curso sobre matēria orgânica do solo. Parte 1. Anälise dos Compostos Hūmicos do Solo, CENA, Piracicaba, $55 \mathrm{p}$.

DEMATTE, J.L.I., 1980. Levantamento Detalhado dos Solos do "Campus" Experimental de Ilha Solteira. Piracicaba, $114 \mathrm{p}$. (mimeografado).

DORADO, E.; J. DEL RIO e A. POLO, 1973. Ácidos húmicos e hymatomelanicos de turbas españolas. Anales de Edafología y Agrobiologia, Madrid, 7-8: 561-572.

ESCOBAR, E.; N. MARTINEZ e M. BLASCO, 1972. Mineralización del carbono y nitrógeno en suelos del Putumayo, Amazonas Colombiana. Efectos de la celulara y temperatura. Turrialba, Turrialba, 1(22): 47-52.

FASSBENDER, H.W., 1978. Química de suelos. San José, Costa Rica, IICA, $398 \mathrm{p}$.

GARGANTINI, H.; F.A.S. COELHO;F. VERLENGLIA e E. SOARES, 1970. Levantamento da fertilidade dos solos do Estado de São Pau1o, Campinas, I.A.C. 32p. (mimeografado).

HALSTEAD, R.L.; A.J. MACLEAN e K.F. NIELSEN, 1958. Ca:Mg ratio in soil and the yield and composition of alfafa. Can. J. of Soil Sci., ottawa, 38(2): 85-93. 
HOYT, P.B., 1977. Effects of organic matter content on exchangeable $\mathrm{Al}$ and $\mathrm{pH}-\mathrm{dependent}$ acidity of very acid soils. Can. J. Soil Sci., Ottawa, 57: 221-222.

KONONOVA, M.M., 1966. Soil organic matter: its role in soil formation and soil fertility. 2.ed. 0xford, Pergamon Press, $544 \mathrm{p}$.

LAROCHE, A.F., 1967. Efeitos da calagem sobre o complexo de troca de um Latossolo tropical e os teores de cátions absorvidos pelo tomate. Recife, SUDENE - Divisão de documentação, $80 \mathrm{p}$. (Sërie Brasil SUDENE Agricultura, 9).

MARTINEZ, B.H.H. e M. BLASCO, 1972. Influencia de los residuos vegetales en el nitrógeno de algunos suelos de cacao en Costa Rica. Turrialba, Turrialba, 3(22): 311-316.

MEHLICH, A. e N.T. COLEMAN, 1952. Type of soil colloid and the mineral nutrition of plants. Advances in Agronomy, New New York, 4: 67-99.

MELO, W.J., 1977. Dinämica de formas de carbono e de nitrogênio em. um Latossol. Roxo cultivado com Sorghum bicolor ( $\mathrm{L}$.) Moench e com Dolichos lab lab L., isolado ou em cultura intercalada. Jaboticabal-SP-F.C.A.V. 118p. |Tese de Livre Docência |

MELO, W.J.; S. BUZETTI; J.M. PIZAURO Jr., 1979. Efeito da incorporação de residuos das culturas de sorgo e labe-labe sobre formas de carbono e de nitrogênio de um Latossol Roxo. In: XVII Congresso Brasileiro de Ciência do Solo, Manaus, Resumos. p. 44 . 
MELLO, F.A.F.; M.C.0. BRASIL SOBR:; S. ARZOLA, 1965. Análises de Solos. Piracicaba, E.S.A. "Luiz de Queiroz", $47 \mathrm{p}$.

MIELNICZUK, J.e I. ANGHINONI, 1976. Aval iação da ut il ização das recomendaçōes de adubo e calcário dos laboratórios of ciais de solos. Trigo e Soja, Porto Alegre, 15:3-6.

NASCIMENTO, V.M. e W.J. MELO, 1981. Efeito da rotação de culturas sobre o teor de matéria orgânica de um solo sob vegetação de cerrado. Relatório trianual apresentado á Universidade Estadual Paulista "Julio de Mesquita Filho"-UNESP. Ilha Solteira, SP, 93p. (não publicado).

-OADES, J.M. e W.N. TOWNSEND, 1963. The influence of iron on the stability of soil organic matter during peroxidation. J. Soil Sci., oxford, $1(14): 134-143$.

ORTEGA, C.; C. FORTUN; A. POLO e E. DORADO, 1979. Estudio de las variaciones en el crecimiento de la raiz de guisante producidas por tres ácidos húmicos. Anales de Edafología y Agrobiologia, Madrid, 7-8: 1399-1407.

POLO, A.; E. DORADO e A.G. VILLARAC0, 1978b. Transformaciōn en la matéria orgánica de suelos sometidos a incubación. Bol. R. Soc. Española Hist. Nat. (Biol.), Madrid, $76: 5-11$.

POLO, A.; E. DORADO; F. VELASCO e A.G. VILLARACO, 1978a. Fracionamiento y estructura de los ácidos húmicos de diversos ecosistemas forestales de la meseta castellana. Bol. R. Soc. Española Hist. Nat. (Biol.), Madrid, 76: 159-169. 
PRATT, P.F., 1966. Quimica do Solo. Rio de Janeiro, MA/ USAID, (1). 88p. (mimeografado).

PRimavesi, A.M., 1973. Influência do teor de cálcio sobre o nivel de matéria orgânica em solos nativos do Rio Grande do Sul. In: XIV Congresso Brasileiro de Ciência do Solo, Santa Maria, Anais. p.389-397.

PRIMAVESI, A.M. 1980. O manejo ecológico do solo. São Paulo, Livraria Nobel S/A, $541 \mathrm{p}$.

SARRUGe, J.R. e H.P. HAAG, 1974. Análises químicas em plantas. Piracicaba. E.S.A. "Luiz de Queiroz", 56p.

SCHNITZER, M. e S.I.M. SKINNER, 1968. Alkali versus acid extraction of soil organic matter. Soil Sci., Baltimore, $6(105): 392-396$.

SCHNITZER, M., 1975. Contribution of organic matter to the cation exchange capacity of soils. Nature, London, 4997 (207): $667-668$.

SOUZA, E.A. e A.M.L. NEPTUNE, 1979. Efeitos da granulometria de calcário dolomitico sobre as propriedades quimicas de um Latossolo. R. bras. Ci. Solo, Campinas, 3: 120-125.

THOMAS, W.G., 1975. The relationship between organic matter content and exchangeable aluminum in acid soil. Soil sci. Soc. Am. Proc., Madison, 39: 591. 
TOLEDO, A.P.P., 1973. Contribuição ao estudo físico-químico de ácido húmico extraído de sedimento. São Paulo - SP, USP, 136p. |Dissertação de Mestrado|

VAN RAIJ, B. e M.A.T. ZULLO, 1977. Métodos de anälises de so10. Campinas, IAC. 16p. (Circular ne 63).

VAN RAIJ, B.; A.P. CAMARG0; H.A.A. MASCARENHAS; R. HIROCE; C.T. FEITOSA; C. NERY e C.R.P. LAUN, 1977. Efeito de niveis de calagem na produção de soja em solo de cerrado. R. bras. Ci. Solo, Campinas, 1: 28-31.

VETTORI, L., 1969. Métodos de anālises de solo. Equipe de Pedologia e Fertilidade do Solo. EPE - M.A., Rio de Janeiro, $24 \mathrm{p}$.

VOLKOFF, B. e M.J. ANDRADE, 1975. Caracterização da matéria orgânica de alguns solos ferroliticos do Estado da Bahia: Aplicação de um método de fracionamento das substâncias húmicas. In: XV Congresso Brasileiro de Ciência do Solo. Campinas, Anais. p.119-126.

WIKLANDER, L., 1964. Cation and anion excharge phenomena. In: F.E. BIER, ed. Chemistry of the soil. 2.ed., New York, Reinhold, p.163-205. 